\title{
Mathematical Analysis of the Effect of Rotor Geometry on Cup Anemometer Response
}

\author{
Ángel Sanz-Andrés, ${ }^{1}$ Santiago Pindado, ${ }^{1,2}$ and Félix Sorribes-Palmer ${ }^{1}$ \\ ${ }^{1}$ Instituto Universitario de Microgravedad "Ignacio Da Riva" (IDR/UPM), Universidad Politécnica de Madrid, \\ ETS de Ingeniería Aeronáutica y del Espacio, Plaza del Cardenal Cisneros 3, 28040 Madrid, Spain \\ ${ }^{2}$ Departamento de Infraestructura, Sistemas Aeroespaciales y Aeropuertos, Universidad Politécnica de Madrid, \\ ETS de Ingeniería Aeronáutica y del Espacio, Plaza del Cardenal Cisneros 3, 28040 Madrid, Spain
}

Correspondence should be addressed to Santiago Pindado; santiago.pindado@upm.es

Received 5 March 2014; Accepted 30 April 2014; Published 3 July 2014

Academic Editor: Ramaswami Balachandar

Copyright (C) 2014 Ángel Sanz-Andrés et al. This is an open access article distributed under the Creative Commons Attribution License, which permits unrestricted use, distribution, and reproduction in any medium, provided the original work is properly cited.

\begin{abstract}
The calibration coefficients of two commercial anemometers equipped with different rotors were studied. The rotor cups had the same conical shape, while the size and distance to the rotation axis varied. The analysis was based on the 2-cup positions analytical model, derived using perturbation methods to include second-order effects such as pressure distribution along the rotating cups and friction. The comparison with the experimental data indicates a nonuniform distribution of aerodynamic forces on the rotating cups, with higher forces closer to the rotating axis. The 2-cup analytical model is proven to be accurate enough to study the effect of complex forces on cup anemometer performance.
\end{abstract}

\section{Introduction}

1.1. Wind Speed Anemometry as an Important Tool in Wind Energy Generation. The importance of accuracy in wind speed measurements is emphasized as the wind energy sector is highly concerned with both wind turbine performance control and wind energy forecast on the field $[1,2]$. The aforementioned accuracy of the measurements directly affects wind energy production, as this production is proportional to the third power of the wind speed [3].

On the other hand, it can be said that today the wind energy sector represents the larger demand of anemometers in the market, despite the increasing use of anemometers in other industries/applications. In addition, it seems that the demand of accurate anemometers will remain strong, although the investment in the wind energy industry has decreased in the traditionally leaders of the sector (Germany, Spain, and Denmark), new players are now very active (China, USA, India, and Brazil) [4].

Finally, the cup anemometer is at present the standardized instrument included in the most relevant code of practice regarding wind turbine power performance measurements (IEC 61400-12-1) [5].
1.2. Cup Anemometer Aerodynamics. A cup anemometer can be studied from two different perspectives: as a meteorological instrument or as a body in autorotation. As a meteorological instrument, the cup anemometer has been studied for a long time, using different techniques and mathematical models, under different climatic conditions and focusing on particular aspects of their performance and response. In addition to these, it should also be said that some important research projects regarding cup anemometers have been carried out based on public funds [6-9]. Table 1 summarizes some of these aspects of cup anemometers, along with the authors of the corresponding research contributions (an extensive review of the available literature has been included in the table).

In many cases, the purpose of the research conducted throughout the twentieth century involved studying certain characteristics of anemometer performance to obtain experimental data in order to develop mathematical models. It must be underlined that a validated mathematical model to predict anemometer performance under normal working conditions is a very useful and important tool in different fields, such as meteorology and the wind energy industry. 
TABLE 1: Research carried out on cup anemometer behavior/performances. References classified by areas of study and research. Some references regarding applications have also been included.

\begin{tabular}{ll}
\hline Research & Mathematical model \\
\hline & \multicolumn{1}{c}{ Static and dynamic respo } \\
& \\
& \\
& \\
& (i) Schrenk 1929 [28] \\
& (ii) Ramachandran 1969 [23] \\
& (iii) Kondo et al. 1971 [24] \\
& (iv) Dahlberg et al. 2001 [8] \\
& (v) Winkel et al. 2007 [29] \\
& (vi) Pindado et al. 2012 [21] \\
Aerodynamic force on the cups; shape of & (vii) Pindado et al. 2013 [22] \\
the anemometer & (viii) Potsdam et al. 2013 [30]
\end{tabular}
Experimental research

(i) Patterson 1926 [31]

(ii) Schrenk 1929 [28]

(iii) Pinkerton 1930 [32]

(iv) Hubbard and Brescoll 1934 [33]

(v) Brevoort and Joyner 1935 [27]

(vi) Fergusson 1939 [34]

(vii) Albright and Klein 1941 [35]

(viii) Fritschen 1967 [36]

(ix) Ramachandran 1969 [23]

(x) Kondo et al. 1971 [24]

(xi) Lindley 1975 [37]

(xii) Lockhart 1985 [38]

(xiii) Pedersen and Paulsen 1999 [39]

(xiv) Dahlberg et al. 2001 [8]

(xv) Hunter et al. 2003 [40]

(xvi) Winkel et al. 2007 [29]

(xvii) Pindado et al. 2011 [20]

(xviii) Pindado et al. 2012 [21]

(xix) Pindado et al. 2013 [22]

(xx) Pindado et al. 2013 [4]

(i) Schrenk 1929 [28]

(ii) Scrase and Sheppard 1944 [41]

(iii) Sanuki 1952 [42]

(iv) Ramachandran 1969 [23]

(v) Ramachandran 1969 [43]

(vi) Torochkov and Surazhskiy 1969 [44]

(vii) Acheson 1970 [45]

(viii) Kondo et al. 1971 [24]

(ix) Hyson 1972 [15]

(x) Wyngaard et al. 1974 [13]

(xi) Kaganov and Yaglom 1976 [11]

(xii) Busch and Kristensen 1976 [18]

(xiii) Busch et al. 1980 [46]

(xiv) Wyngaard 1981 [14]

(xv) Coppin 1982 [16]

(xvi) Hayashi 1987 [47]

(xvii) Frenzen 1988 [48]

(xviii) Snow et al. 1989 [49]

(xix) Chang and Frenzen 1990 [17]

(xx) Hunter 1990 [50]

(xxi) Skarstein et al. 1992 [51]

(xxii) Kristensen 1993 [52]

(xxiii) Kristensen 1994 [53]

(xxiv) Fabian 1995 [54]

(xxv) Westermann 1996 [55]

(xxvi) Kristensen 1998 [19]

(xxvii) Hristov et al. 2000 [56]

(xxviii) Kristensen 2000 [57]

(xxix) Dahlberg et al. 2001 [8]

(xxx) Kristensen 2002 [3]

(xxxi) Kristensen and Hansen 2002 [58]

(xxxii) Pedersen 2003 [10]

(xxxiii) Kristensen et al. 2003 [59]

(xxxiv) Pedersen 2004 [60]

(xxxv) Solov'ev et al. 2004 [12]

(xxxvi) Yahaya and Frangi 2004 [61]

(xxxvii) Kristensen and Hansen 2005 [62]

(xxxviii) Dahlberg et al. 2006 [9]

(xxxix) Bégin-Drolet et al. 2011 [63]

(xl) Pindado et al. 2012 [21]

(xli) Bégin-Drolet et al. 2013 [64] (i) Brazier 1921 [65]

(ii) Schrenk 1929 [28]

(iii) Marvin 1932 [66]

(iv) Marvin 1934 [67]

(v) Spilhaus and Rossby 1934 [68]

(vi) Brevoort and Joyner 1935 [27]

(vii) Fergusson 1939 [34]

(viii) Scrase and Sheppard 1944 [41]

(ix) Deacon 1951 [69]

(x) MacCready 1966 [70]

(xi) Bernstein 1967 [71]

(xii) Izumi and Barad 1970 [72]

(xiii) Camp et al. 1970 [73]

(xiv) Kondo et al. 1971 [24]

(xv) Hyson 1972 [15]

(xvi) Lindley and Bowen 1974 [74]

(xvii) Wyngaard et al. 1974 [13]

(xviii) Lindley 1975 [37]

(xix) Baynton 1976 [75]

(xx) Busch et al. 1980 [46]

(xxi) Coppin 1982 [16]

(xxii) Hayashi 1987 [47]

(xxiii) Hunter 1990 [50]

(xxiv) Morris et al. 1992 [76]

(xxv) Fabian 1995 [54]

(xxvi) Westermann 1996 [55]

(xxvii) Kristensen 2000 [57]

(xxviii) Dahlberg et al. 2001 [8]

(xxix) Pedersen 2003 [10]

(xxx) Hunter et al. 2003 [40]

(xxxi) Pedersen 2004 [60]

(xxxii) Solov'ev et al. 2004 [12]

(xxxiii) Pedersen and Paulsen 1999 [39]

(xxxiv) Kristensen 2002 [58]

(xxxv) Yahaya and Frangi 2004 [61]

(xxxvi) Dahlberg et al. 2006 [9]

(xxxvii) Pedersen et al. 2006 [77]

(xxxviii) Bégin-Drolet et al. 2011 [63]

(xxxix) Pindado et al. 2012 [21]

(xl) Bégin-Drolet et al. 2013 [64]

(xli) Pindado et al. 2013 [22]

(xlii) Pindado et al. 2013 [4] 
TABle 1: Continued.

\begin{tabular}{|c|c|c|}
\hline Research & Mathematical model & Experimental research \\
\hline Effect of bearings system; friction. & $\begin{array}{l}\text { (i) Fabian } 1995 \text { [54] } \\
\text { (ii) Pedersen and Paulsen } 1999 \text { [39] } \\
\text { (iii) Dahlberg et al. 2001 [8] } \\
\text { (iv) Pedersen } 2003 \text { [10] } \\
\text { (v) Pedersen } 2004 \text { [60] } \\
\text { (vi) Dahlberg et al. 2006 [9] }\end{array}$ & $\begin{array}{l}\text { (i) Baynton } 1976 \text { [75] } \\
\text { (ii) Fabian } 1995 \text { [54] } \\
\text { (iii) Pedersen and Paulsen 1999 [39] } \\
\text { (iv) Dahlberg et al. 2001 [8] } \\
\text { (v) Pedersen } 2003 \text { [10] } \\
\text { (vi) Pedersen } 2004 \text { [60] } \\
\text { (vii) Dahlberg et al. 2006 [9] } \\
\text { (viii) Pedersen et al. 2006 [77] }\end{array}$ \\
\hline Performance degradation & $\begin{array}{l}\text { (i) Siegel and Lee } 2011[78] \\
\text { (ii) Cassity et al. } 2012[79] \\
\text { (iii) Sun et al. } 2012 \text { [80] }\end{array}$ & $\begin{array}{l}\text { (i) Zlatanovic and Zlatanovic } 2012 \text { [81] } \\
\text { (ii) Pindado et al. } 2012 \text { [82] }\end{array}$ \\
\hline $\begin{array}{l}\text { Sampling; filtering; correction of the } \\
\text { measured velocity }\end{array}$ & $\begin{array}{l}\text { Output signal post-processing } \\
\text { (i) Wieringa } 1980 \text { [83] } \\
\text { (ii) Wyngaard et al. 1982 [84] } \\
\text { (iii) Moore 1986 [85] } \\
\text { (iv) Hayashi } 1987 \text { [47] } \\
\text { (v) Skarstein et al. 1992 [51] } \\
\text { (vi) Ebert et al. } 1995 \text { [86] } \\
\text { (vii) Barnard et al. } 1998 \text { [87] } \\
\text { (viii) Hristov et al. } 2000 \text { [56] } \\
\text { (ix) Kristensen et al. 2003 [59] } \\
\text { (x) Selyaninov 2004 [88] } \\
\text { (xi) Solov'ev et al. 2004 [12] } \\
\text { (xii) Yahaya and Frangi 2004 [61] } \\
\text { (xiii) Siegel and Lee 2011 [78] } \\
\text { (xiv) Bégin-Drolet et al. 2013 [64] }\end{array}$ & $\begin{array}{l}\text { (i) Bernstein } 1967 \text { [71] } \\
\text { (ii) Wieringa } 1980 \text { [83] } \\
\text { (iii) Wyngaard et al. 1982 [84] } \\
\text { (iv) Hayashi } 1987 \text { [47] } \\
\text { (v) Ebert et al. } 1995 \text { [86] } \\
\text { (vi) Solov'ev et al. 2004 [12] } \\
\text { (vii) Yahaya and Frangi 2004 [61] } \\
\text { (viii) Bégin-Drolet et al. } 2013 \text { [64] }\end{array}$ \\
\hline
\end{tabular}

Performance on the field

Climatic conditions (change of air density, rain, ice, extreme weather conditions, etc.)

Anemometer allocation on towers (i) Wieringa 1980 [83]

(ii) Wyngaard 1981 [96]

(iii) Wyngaard et al. 1982 [84]

(iv) Hansen and Pedersen 1999 [97]

(v) Lubitz 2009 [98] (i) Gates and Thompson 1986 [91]

(ii) Kimura et al. 2001 [92]

(iii) Makkonen et al. [93]

(iv) Fortin et al. 2005 [90]

(v) Pindado et al. 2012 [94]

(vi) Hobby et al. 2013 [95]

(i) Izumi and Barad 1970 [72]

(ii) Burt 1975 [99]

(iii) Wieringa 1980 [83]

(iv) Wyngaard et al. 1982 [84]

(v) Morris et al. 1992 [76]

(vi) Pedersen et al. 1992 [100]

(vii) Hunter et al. 2003 [40]

(viii) Orlando et al. 2011 [101]

(ix) Farrugia and Sant 2013 [102]

(i) Camp 1966 [104]

(ii) Kristensen et al. 1991 [103]

(iii) Petersen et al. 1998 [105]

(iv) Albers et al. 2000 [7]

(v) Albers and Klug 2001 [6]

(vi) Papadopoulos et al. 2001 [106]

(vii) Hunter et al. 2001 [107]

(viii) Paulsen et al. 2007 [108]

(ix) Wagner et al. 2011 [109]

(x) Lang and McKeogh 2011 [110]

(xi) Bradley 2013 [111]

(xii) Hasager et al. 2013 [112]

(xiii) Sanz Rodrigo et al. 2013 [113] 
TABle 1: Continued.

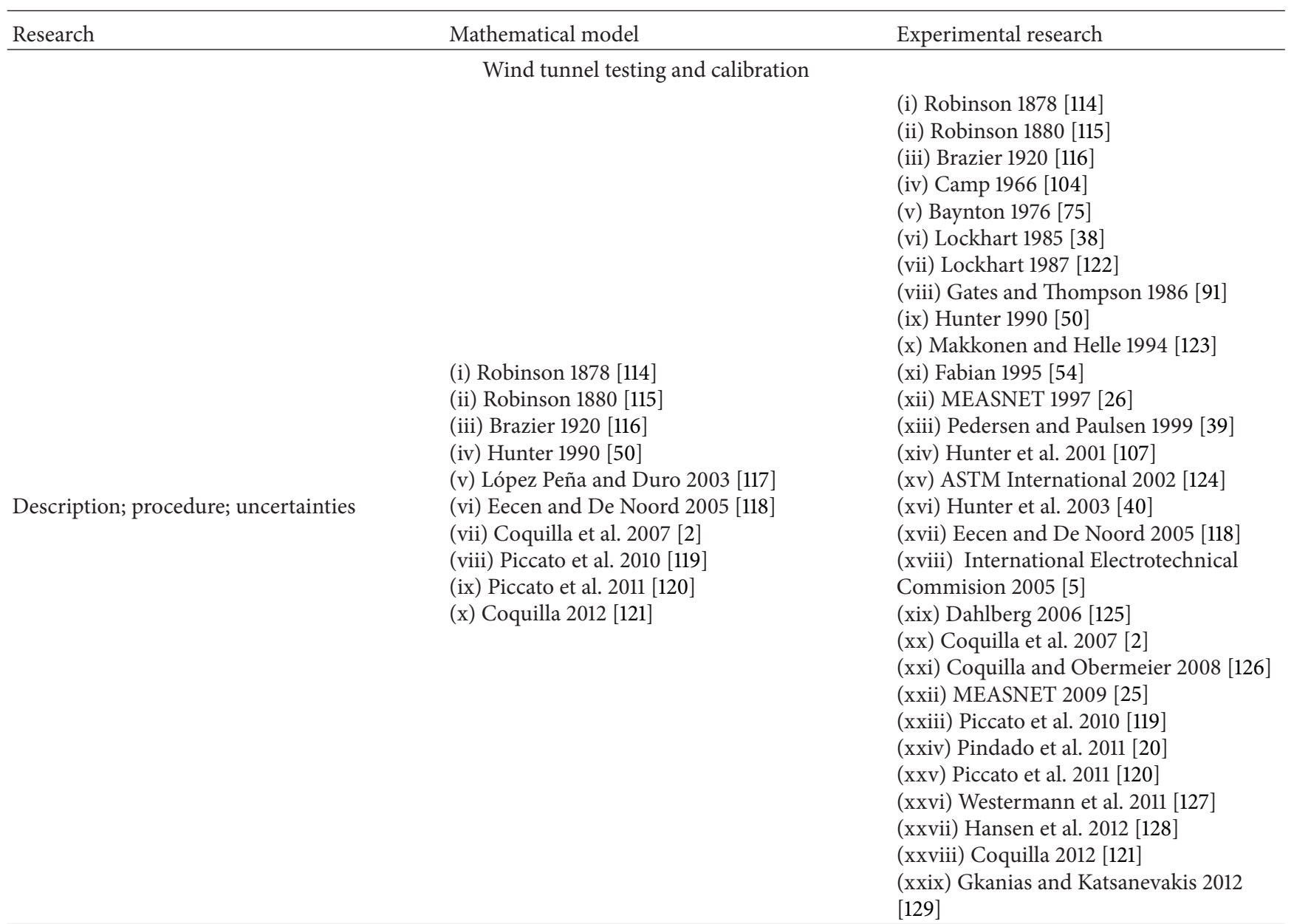
[129]

\begin{tabular}{lll} 
& (i) McBean 1972 [130] & (i) Sheppard et al. 1972 [131] \\
Instrumentation & (ii) Sheppard et al. 1972 [131] & (iii) Lockhart 1985 [38] \\
& (iv) Moore 1986 [85] & \\
\hline
\end{tabular}

Design and performance

(i) Pedersen and Paulsen 1999 [39]
(ii) Kristensen 2002 [58]
(iii) Pedersen 2003 [10]
(iv) Pedersen 2004 [60]
(v) Dahlberg et al. 2006 [9]
(vi) Pindado et al. 2013 [22]
(i) Frenzen 1968 [132]
(ii) Wellman 1968 [133]
(iii) Mazzarella 1972 [134]
(iv) Lindley 1975 [37]
(v) Pedersen and Paulsen 1999 [39]
(vi) Dahlberg et al. 2001 [8]
(vii) Kristensen 2002 [58]
(viii) Pedersen 2003 [10]
(ix) Pedersen 2004 [60]
(x) Dahlberg et al. 2006 [9]
(xi) Pedersen et al. 2006 [77]
(xii) Choon et al. 2012 [135]
(xiii) Pindado et al. 2013 [22]

Mathematical models normally include Euler's equation for describing the rotation of a rigid body (anemometer cup rotor), affected by both aerodynamic and friction torque [5]:

$$
I \frac{\mathrm{d} \omega}{\mathrm{d} t}=M_{A}+M_{f}
$$

where $\omega$ is the rotational speed of the anemometer rotor, $I$ is the moment of inertia, $M_{A}$ is the aerodynamic torque, and $M_{f}$ is the frictional torque that depends on the air temperature, $T$, and the rotation speed, $\omega$ (from [10]: $M_{f}=$ $B_{0}(T)+B_{1}(T) \omega+B_{2}(T) \omega^{2}$, where coefficients $B_{0}, B_{1}$, and $B_{2}$ are negative (the friction torque, $M_{f}$, in expression (1) has a negative sign in the updated version of [5]. Therefore, 


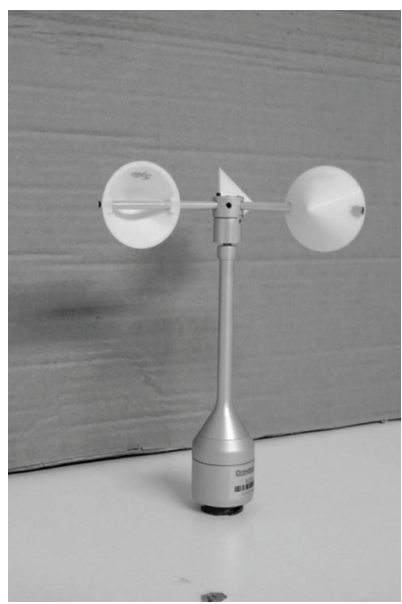

(a)

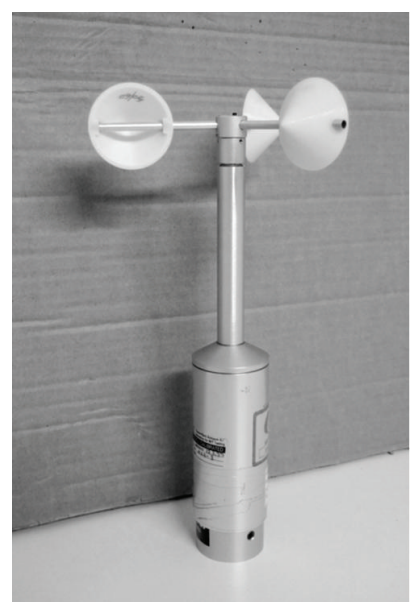

(b)
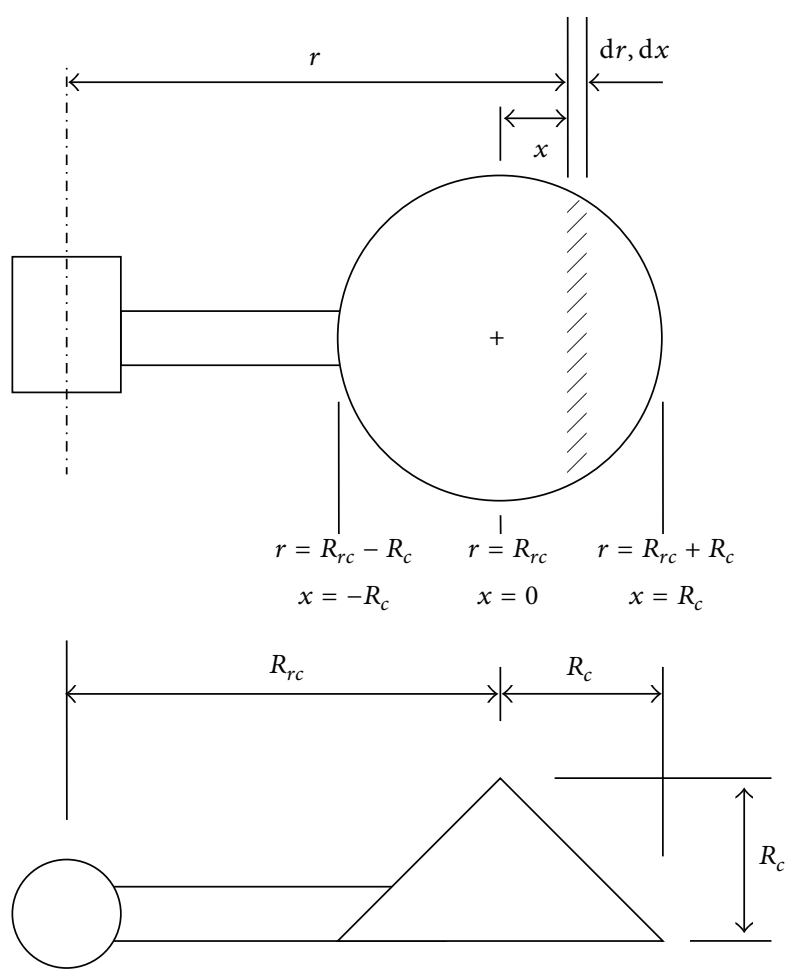

(c)

FIgURE 1: Anemometers used in the testing campaign related to the calibration results from Table 2, Climatronics 100075 (b) and Ornytion $107 \mathrm{~A}$ (a). A sketch of the conical cups of the rotors tested is also included (c).

coefficients $B_{0}, B_{1}$, and $B_{2}$ of the friction torque expression will be positive, if this is taken into account)). The frictional torque, $M_{f}$, is generally neglected in all mathematical models [10], as it is very low compared to the aerodynamic torque within the normal wind speed range $[11,12]$. The aerodynamic torque is modeled as a function that includes the wind speed, $V$, the cup center rotation speed, $\omega R_{r c}\left(R_{r c}\right.$ is the cup center rotation radius, see Figure 1), and the vertical component of the wind speed, $w$. This function is derived using nondimensional and perturbation analysis to the second-order Taylor polynomial, where the coefficients are measured by means of carefully planned testing [11, 13-19]. This method was therefore developed to correlate a group of parameters with a specific individual anemometer, in order to obtain the highest possible accuracy in the predictions relating to dynamic behavior (i.e., accelerations and decelerations of the rotor from a steady situation, at constant rotational speed). This procedure requires no aerodynamic model of the rotating body or rotor.

However, a properly developed aerodynamic model of the rotor can be very interesting, as the effect of certain parameters can be identified to provide a better understanding of cup anemometer performance. Some efforts have been made to integrate rotational aerodynamics in the mathematical 


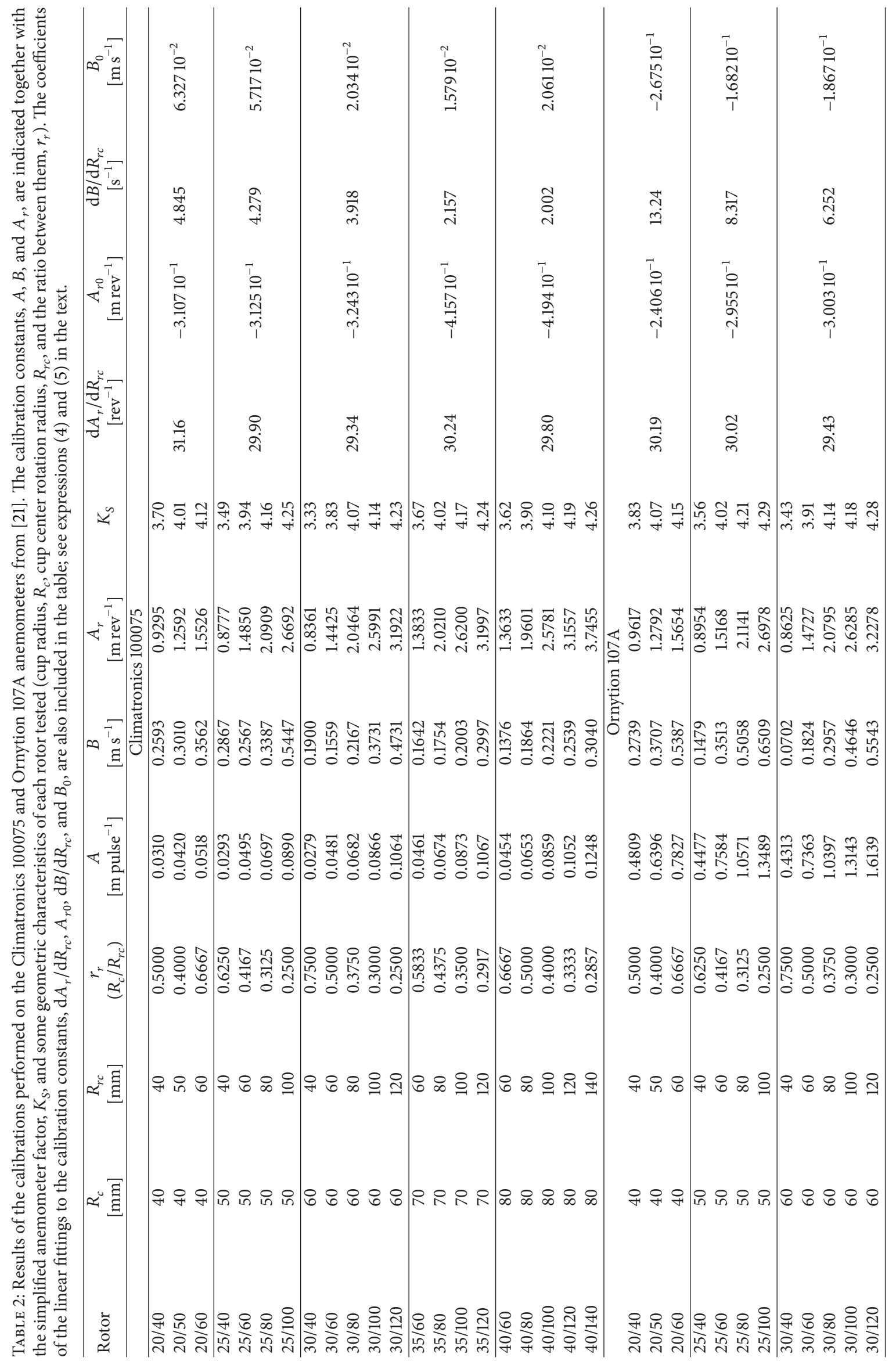




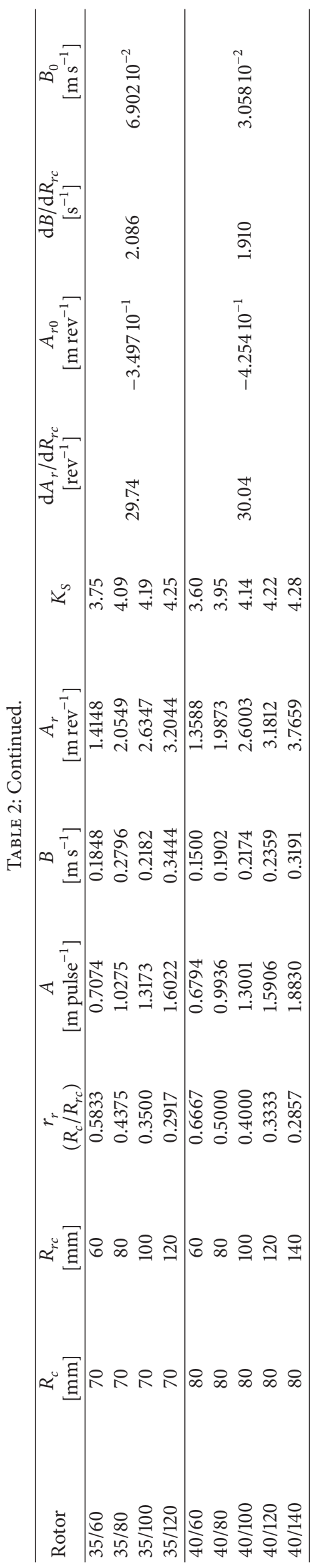


models with interesting results [14, 20-24]. Nevertheless, it is fair to say that, due to the simplifications in the development of these models, some deviations remain when compared to the experimental results $[21,22]$.

The aim of this paper is to continue with the postprocessing of the experimental results from the systematic cup anemometer testing campaign carried out at the IDR/UPM Institute during 2011 and to derive a simple mathematical model for studying some aspects of cup anemometer performance. The testing campaign consisted of 21 calibrations performed on 2 different anemometers (Climatronics 100075 and Ornytion 107A, see Figure 1), while varying the cup radius, $R_{c}$, and the cup center rotation radius, $R_{r c}$, of the rotor (more information regarding the testing campaign can be found in [21]). Table 2 includes the calibration results from that campaign (details concerning the calibration facility are included in Appendix A). These results are the slope and offset of the transfer function (commonly known as calibration constants $A$ and $B[25,26])$ :

$$
V=A \cdot f+B \text {. }
$$

This transfer function, obtained experimentally in a wind tunnel, relates the wind speed to the output frequency of the anemometer, $f$ (see Appendix A). The slope of the transfer function given in terms of rotational frequency, $f_{r}$, instead of output frequency, $f$ :

$$
V=A_{r} \cdot f_{r}+B
$$

is also included in Table 2. This new slope, $A_{r}$, is the result of multiplying calibration constant $A$ by the number of pulses per turn, $N_{p}$, given by the anemometer. (The Climatronics 100075 and Ornytion 107A anemometers give 30 and 2 pulses per turn, respectively [20].) Finally, the coefficients $\mathrm{d} A_{r} / \mathrm{d} R_{r c}$, $\mathrm{d} B / \mathrm{d} R_{r c}, A_{r 0}$, and $B_{0}$, (slope and offset) of the linear fittings with regard to the calibration coefficients, $A_{r}$ and $B$, as a function of the cup center rotation radius, $R_{r c}$

$$
\begin{gathered}
A_{r}=\frac{\mathrm{d} A_{r}}{\mathrm{~d} R_{r c}} R_{r c}+A_{r 0}, \\
B=\frac{\mathrm{d} B}{\mathrm{~d} R_{r c}} R_{r c}+B_{0},
\end{gathered}
$$

calculated for rotors with cups of the same radius, $R_{c}$, are included in Table 2, along with the aforementioned results. The above equations were important for deriving the following experimentally fitted expressions [21]:

$$
\begin{aligned}
A_{r} & =\frac{\mathrm{d} A_{r}}{\mathrm{~d} R_{r c}} R_{r c}-S_{c}\left(\zeta+\eta S_{c}^{-\xi}\right), \\
B & =\left(\varepsilon+\phi S_{c}^{-\gamma}\right) R_{r c}-\mu S_{c}^{-\psi} .
\end{aligned}
$$

The most relevant conclusions reached were as follows.

(i) The slope of the calibration transfer function, $A_{r}$, depends on two different contributions, one related to the cup center rotation radius, $R_{r c}$, and the other related to the cups' front area, $S_{c}$, or cup radius, $R_{c}\left(S_{c}=\pi R_{c}^{2}\right)$. The slope of expression (6), $\mathrm{d} A_{r} / \mathrm{d} R_{r c}$, seems to be directly related to the aerodynamic nondimensional coefficient of the cups, as very small differences in this coefficient were observed among the 42 calibrations performed on the 2 anemometers tested. That is, the fitting coefficient $\mathrm{d} A_{r} / \mathrm{d} R_{r c}$ did not seem to depend on the anemometer, with the same value for both the Climatronics 100075 and the Ornytion 107A anemometers, whereas the other fitting coefficients, $\zeta, \eta$, and $\xi$, were different depending on the anemometer tested.

(ii) The offset of the calibration transfer function, $B$, also depends on the same shape parameters, although in this case each contribution is not totally independent from the next. In this case, all the fitting parameters, $\varepsilon, \gamma, \phi, \mu$, and $\psi$, were different depending on the anemometer tested.

In the research described, cup anemometer performance was analyzed using the anemometer factor, $K$, which relates the wind speed, $V$, to the cup center rotation speed, $\omega R_{r c}$; that is, $K=V / \omega R_{r c}$. In the calculations of this factor from the calibration results, the offset constant, $B$, is usually neglected because it is small compared to the wind speed within the normal working range of the anemometer (average values of calibration constant $B$ for three Class- 1 anemometers are $0.179 \mathrm{~m} \mathrm{~s}^{-1}$ (Risø P2546A), $0.248 \mathrm{~m} \mathrm{~s}^{-1}$ (Thies Clima 4.3350), and $0.184 \mathrm{~m} \mathrm{~s}^{-1}$ (Vector Instruments A100 L2) [20]. The calibration range of an anemometer, according to MEASNET is from $4 \mathrm{~m} \mathrm{~s}^{-1}$ to $16 \mathrm{~m} \mathrm{~s}^{-1}$ [25], although sometimes the upper limit of this calibration range is larger [20]). Nevertheless, the anemometer factor does indeed depend on the offset constant:

$$
K=\frac{V}{\omega R_{r c}}=\frac{A_{r} f_{r}+B}{2 \pi f_{r} R_{r c}}=\frac{A_{r}}{2 \pi R_{r c}} \frac{1}{1-(B / V)} .
$$

Moreover, in a recent study at the IDR/UPM Institute, differences of up to $13.4 \%$ were observed at a wind speed of $V=4 \mathrm{~m} / \mathrm{s}$ regarding the anemometer factor, $K$, if the offset constant is taken into account [4]. To avoid this possible source of misunderstandings, a simplified anemometer factor, $K_{S}$, is proposed in this paper:

$$
K_{S}=\frac{V-B}{\omega R_{r c}}=\frac{A_{r}}{2 \pi R_{r c}} .
$$

Figure 2 includes the simplified anemometer factor (hereinafter, anemometer factor), $K_{S}$, calculated with the results from Table 2. It must also be said that in previous studies $[4,22]$, the anemometer factor was regarded as displaying quadratic behavior as a function of the ratio of cup radius to cup center rotation radius, $r_{r}=R_{c} / R_{r c}$. This consideration was based on the assumption of asymptotic behavior for low values of the aforementioned parameter $\left(r_{r} \rightarrow 0\right)$. This seems reasonable because in this case the analytical models showed a lower dependence on $r_{r}$ [22]. However, the linear fittings to the data from Figure 2 show rather high determination coefficients, $R^{2}$, with minimum and average values of $R^{2}=0.965$ and $R^{2}=0.985$, respectively. This indicates linear rather than quadratic behavior within the normal range of 


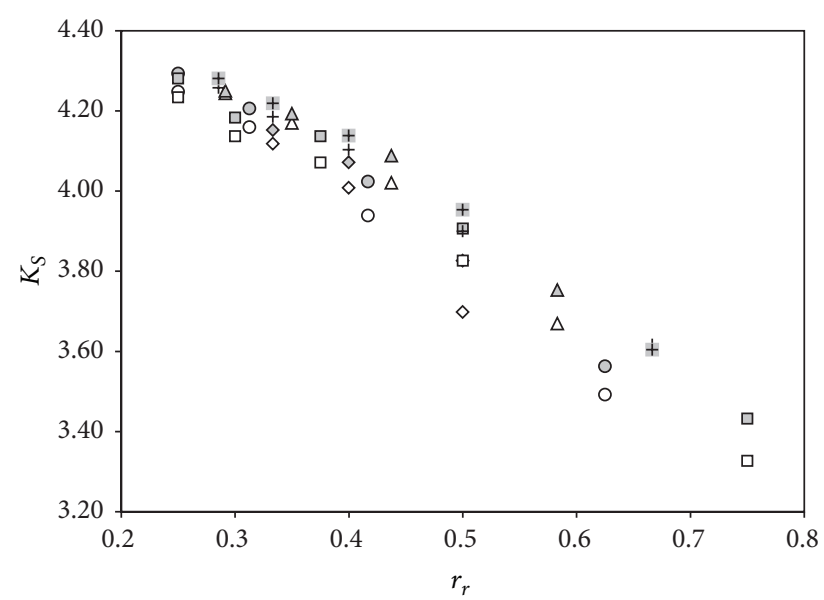

$$
\begin{array}{ll}
\diamond \text { Cl 100075, } R_{c}=20 \mathrm{~mm} & \square \text { Ory 107A, } R_{c}=30 \mathrm{~mm} \\
\diamond \text { Ory 107A, } R_{c}=20 \mathrm{~mm} & \Delta \text { Cl 100075, } R_{c}=35 \mathrm{~mm} \\
\circ \text { Cl 100075, } R_{c}=25 \mathrm{~mm} & \Delta \text { Ory 107A, } R_{c}=35 \mathrm{~mm} \\
\circ \text { Ory 107A, } R_{c}=25 \mathrm{~mm} & + \text { Cl 100075, } R_{c}=40 \mathrm{~mm} \\
\square \text { Cl 100075, } R_{c}=30 \mathrm{~mm} & + \text { Ory 107A, } R_{c}=40 \mathrm{~mm}
\end{array}
$$

FIGURE 2: Simplified anemometer factor, $K_{S}$, as a function of the ratio of the cup radius to the cup center rotation radius, $r_{r}\left(r_{r}=\right.$ $\left.R_{c} / R_{r c}\right)$, regarding the calibrations performed on the Climatronics 100075 anemometer ( $\mathrm{Cl} \mathrm{100075}$; white symbols) and the Ornytion 107A anemometer (Ory 107A; grey symbols) [21]. Both were equipped with $R_{c}=20 \mathrm{~mm}$ cups (rhombi), $R_{c}=25 \mathrm{~mm}$ cups (circles), $R_{c}=30 \mathrm{~mm}$ cups (squares), $R_{c}=35 \mathrm{~mm}$ cups (triangles), and $R_{c}=40 \mathrm{~mm}$ cups (crosses).

parameter $r_{r}$. Also, taking into account expressions (6) and (9), the following equation can be derived:

$$
K_{S}=\frac{1}{2 \pi}\left[\frac{\mathrm{d} A_{r}}{\mathrm{~d} R_{r c}}-\left(\zeta^{\prime} R_{c}+\frac{\eta^{\prime}}{R_{c}^{2 \xi-1}}\right) r_{r}\right],
$$

which is in agreement with the linear behavior mentioned above. Obviously, in the expression above, $\zeta^{\prime}$ and $\eta^{\prime}$ are derived from the fitting coefficients $\zeta$ and $\eta$ in (6).

To develop a mathematical model, the aerodynamic torque should be considered proportional to the dynamic pressure relative to the cup. On the other hand, because a dynamic problem is considered, the aerodynamic torque should be described in terms of a nondimensional parameter, $\Omega=\omega R_{r c} / V$, formed by the rotational speed, $\omega$, which is inversely proportional to the characteristic time of the movement, and the residence time, $V R_{r c}$, comprised the wind speed, $V$, and a characteristic length of the rotor, $R_{r c}$. This parameter, $\Omega$, is also called the cup center nondimensional velocity.

In this regard, Figure 3 shows the experimental results from Brevoort and Joyner [27] and Wyngaard et al. [13]. In these graphs, the aerodynamic torque, $M_{A}$, is shown as a function of the dimensionless parameter $\Omega$. The nondimensional aerodynamic torque, $m_{A}$ (see expression (12)), is also shown. It can be observed that the nondimensional curves tend to collapse into a single curve, revealing the relationship between the aforementioned dimensionless parameters, $m_{A}$ and $\Omega$. This behavior was also analyzed by Pedersen [10], who found a second-order polynomial relationship between the nondimensional aerodynamic torque, $m_{A}$, and the speed ratio (the speed ratio is defined in [5] as $V$ and $V_{t}$, which are the wind speed at the calibration facility and the threshold velocity, respectively. The threshold velocity is derived by subtracting the friction effects from the calibration offset, $B$ ), $\lambda=\omega R_{r c} /\left(V-V_{t}\right)$.

The classical model for aerodynamic torque is represented by the following expression:

$$
\begin{aligned}
M_{A}= & \frac{1}{2} \rho S_{c} R_{r c} N_{c} \\
& \times\left[\left(V-\omega R_{r c}\right)^{2} c_{1} C_{D 1}-\left(V+\omega R_{r c}\right)^{2} c_{2} C_{D 2}\right],
\end{aligned}
$$

where $\rho$ is the air density, $N_{c}$ the number of cups, $S_{c}$ the front area of the cups, $V$ the wind speed, $\omega$ the rotational speed, $C_{D 1}$ (concave side) and $C_{D 2}$ (convex side) are the aerodynamic drag force coefficients of the cups, and $c_{1}$ and $c_{2}$ are coefficients that take into account the effectiveness of the aerodynamic simplification. The average torque produced by each cup is then expressed as a function of the forces at only two positions. See Figure 4 for the normal-to-the-cup aerodynamic coefficient, $c_{N}$, with regard to a nonrotating cup expressed as a function of the wind direction, $\alpha$. The dashed line in the figure represents the approximation of aerodynamic torque produced by one cup shown in expression (11). That expression can be rewritten in nondimensional form:

$$
\begin{aligned}
m_{A} & =\frac{M_{A}}{(1 / 2) \rho S_{c} R_{r c} V^{2}} \\
& =N_{c}\left[(1-\Omega)^{2} c_{1} C_{D 1}-(1+\Omega)^{2} c_{2} C_{D 2}\right] \\
& =N_{c} c_{1} C_{D 1}\left[(1-\Omega)^{2}-k_{D}^{2}(1+\Omega)^{2}\right],
\end{aligned}
$$

where the dependence on the nondimensional parameter $\Omega$ is reflected. Also, a new parameter is included in the equation, the drag coefficient ratio, $k_{D}$,

$$
k_{D}=\left(\frac{c_{2} C_{D 2}}{c_{1} C_{D 1}}\right)^{1 / 2} \text {. }
$$

With this model, the equilibrium point, $m_{A}=0$, is obtained for

$$
\Omega=\Omega_{0}=\frac{1-k_{D}}{1+k_{D}} .
$$

Theoretical equation (12) has been fitted to the graphs for the nondimensional torque included in Figure 3. The results are in good correspondence with the experimental results, indicating the validity of this analytical approach. The simplification made with (11) is also known as the 2-cup analytical model, which models the anemometer's behavior with a rotor consisting of $N_{c}$ cups whose aerodynamic moment along one turn is characterized by the two more relevant positions with respect to the wind, $\alpha=0^{\circ}$ and $\alpha=180^{\circ}$, see Figure 4 . For the equilibrium point, $m_{A}=0$, the rotor can be idealized as a 2-cup rotor with cups, respectively, positioned at the aforementioned angles $\alpha=0^{\circ}$ (wind pointing to the concaveside of one cup) and $\alpha=180^{\circ}$ (wind pointing to the convexside of the other cup). This situation is sketched in Figure 4. 

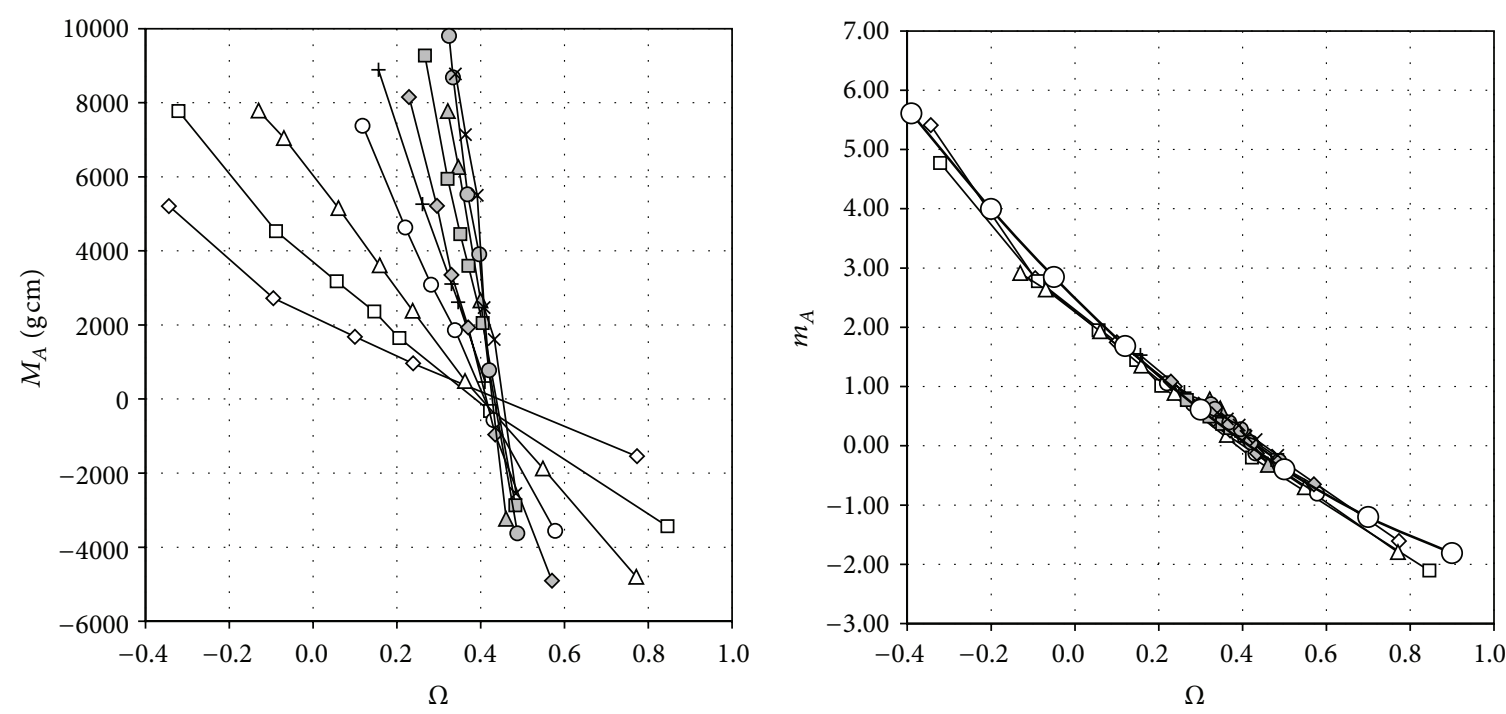

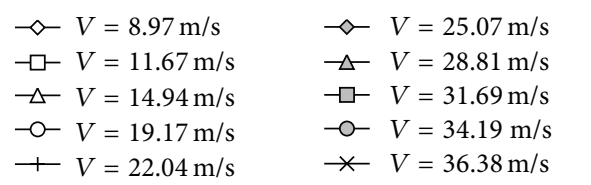

(a)

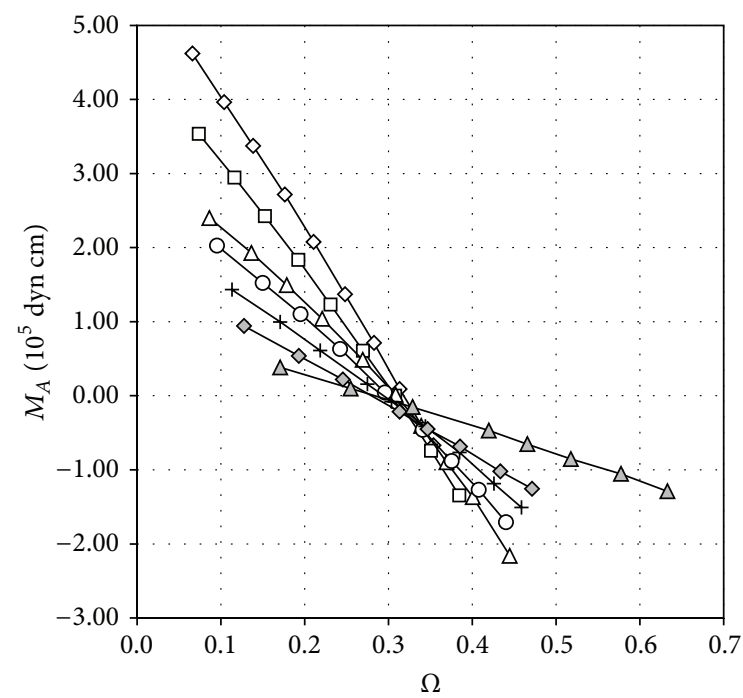

$$
\begin{aligned}
& \multimap V=7.05 \mathrm{~m} / \mathrm{s} \\
& \neg-V=6.42 \mathrm{~m} / \mathrm{s} \\
& \neg-V=5.51 \mathrm{~m} / \mathrm{s}
\end{aligned}
$$$$
-0-V=5.00 \mathrm{~m} / \mathrm{s}
$$

$$
\begin{aligned}
& \checkmark V=8.97 \mathrm{~m} / \mathrm{s} \quad \neg-V=28.81 \mathrm{~m} / \mathrm{s} \\
& \neg-V=11.67 \mathrm{~m} / \mathrm{s} \\
& \neg-V=14.94 \mathrm{~m} / \mathrm{s} \\
& -0-V=19.17 \mathrm{~m} / \mathrm{s} \\
& +V=22.04 \mathrm{~m} / \mathrm{s} \\
& \prec-V=25.07 \mathrm{~m} / \mathrm{s}
\end{aligned}
$$

(b)

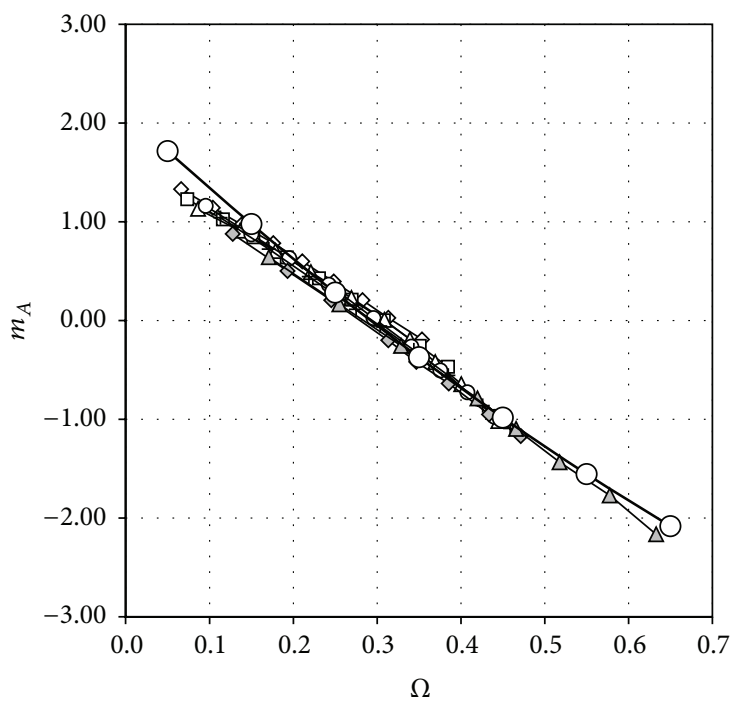

$$
\begin{aligned}
& \multimap-V=7.05 \mathrm{~m} / \mathrm{s} \\
& \neg-V=6.42 \mathrm{~m} / \mathrm{s} \\
& -\checkmark V=5.51 \mathrm{~m} / \mathrm{s} \\
& \multimap-V=5.00 \mathrm{~m} / \mathrm{s}
\end{aligned}
$$

(c)

(d)

FIgURE 3: Aerodynamic torque, $M_{A}$, measured on 4-cup [27] (a) and 3-cup [13] (c) anemometers as a function of the ratio between the cup center velocity and the wind speed, $\Omega\left(\Omega=\omega R_{r c} / V\right)$. The nondimensional torque, $m_{A}$, calculated for each curve, has also been included ((b) and $(\mathrm{d})$ ), together with the results from the classical theoretical model fitted to the curves; see expression (12).

1.3. Aim of the Present Work. As explained in the previous subsection, the aim of the present paper is to derive a mathematical model with a strong aerodynamic basis, which could help to explain its behavior as a function of certain parameters. To do so the paper has been organized as follows. Section 2 describes a mathematical (analytical) model for analyzing cup anemometer behavior. This model is based on the classical 2-cup positions model explained earlier. Although the results from the classical model show some limitations for drag coefficient ratios outside the normal ranges [21] (Brevoort and Joyner [27] measured drag coefficients ratio, $C_{D 2} / C_{D 1}$, for different cup shapes 


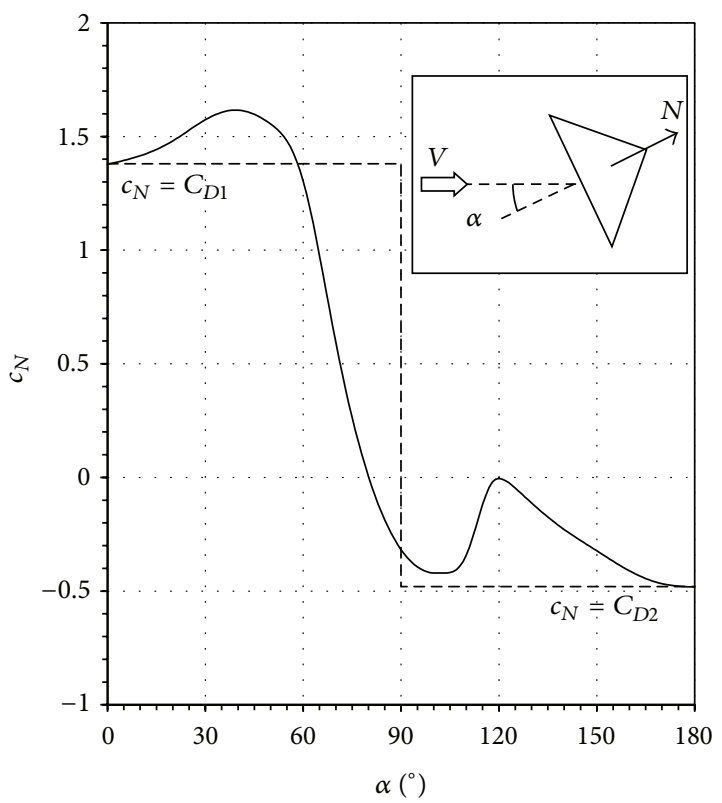

— Brevoort and Joyner (1935). Type II-cup --- Simplified model
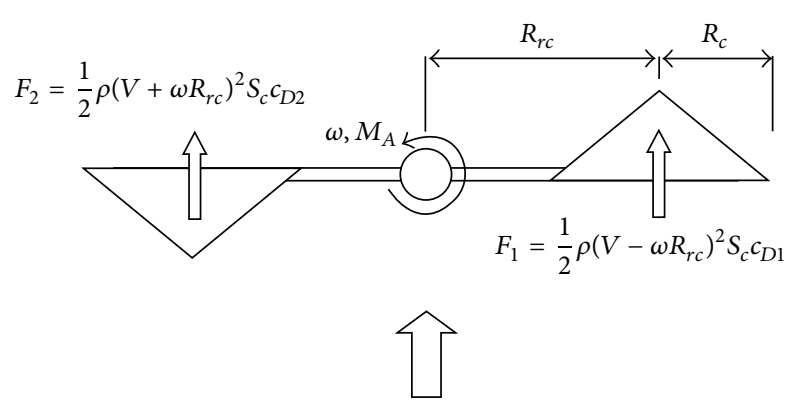

V

FIGURE 4: Normal aerodynamic force coefficient, $c_{N}$, of the Brevoort and Joyner Type-II cup [27], plotted as a function of the wind direction with respect to the cup, $\alpha$. The approximation used in the classical simplified model for aerodynamic torque on the anemometer rotor (expression (11)) is also included as a dashed line. See in the attached sketch the idealized approximation to the equilibrium point of the 2-cup analytical model, where $M_{A}=0, F_{1}=F_{2}$, and, therefore, the rotation speed $\omega$ is constant.

in the bracket $(0.26,0.36)$, whereas Schrenk [28] measured $C_{D 2} / C_{D 1}=0.25$ for hemispherical cups), it has proven strong enough to provide well-founded explanations of cup anemometer performance $[14,28]$ and also correlated well with data resulting from the analysis of several commercial cup anemometers [20]. In Section 3, the model is correlated with the results from Table 2 . Finally, conclusions are summarized in Section 4.

\section{Mathematical Model}

As stated above, the aim of this paper is to derive a model simple enough to analytically study cup anemometer behavior but also complex enough to include the parameters most relevant to the problem. In this sense, simple classical analytical approximations are unable to reflect the influence of cup size (i.e., cup radius, $R_{c}$ ), in the solution for the equilibrium state $\left(m_{A}=0\right.$; see expressions (12), (13), and (14)) [21, 22]. To overcome this limitation, a nonconstant force distribution on the cup is considered.

The normal-to-the-cup force, $N$ (see Figure 4), is generally expressed as

$$
N=\frac{1}{2} \rho V_{r}^{2} S_{c} c_{N}
$$

where $V_{r}$ is the relative-to-the-cup wind speed, $S_{c}$ is the cup's front area, and $c_{N}$ is the normal-to-the-cup force coefficient (which depends on the angle of $V_{r}$ with respect to the cup). This force coefficient is normally measured by static wind tunnel testing of an isolated cup, which does not take into account any rotating flow around the cup [21, 22, 27]. Nevertheless, expression (15) is a good approximation for low values of the parameter $r_{r}$ (i.e., large cup center rotation radius, $R_{r c}$, in comparison to the cup radius, $R_{c}$ ). Some efforts have already been made to include the aforementioned rotating flow effect, considering the dynamic pressure relative to the cup as a function of the distance to the rotation axis [22]. However, the results were not relevant because the normalto-the-cup aerodynamic coefficient, $c_{N}$, was still considered constant all over the front surface of the cup, and was based on static wind tunnel measurements. As a result, this paper considers a non-constant pressure distribution on the front area of the cups. The aerodynamic forces on the cup arm are also considered in the mathematical approximation.

The torque on one cup at position $\alpha=0^{\circ}$ (see Figure 4) is then defined by the following equation:

$$
\begin{array}{r}
M_{1}=\frac{1}{2} \rho\left[\int_{R_{r c}-R_{c}}^{R_{r c}+R_{c}} g_{1}(r)(V-\omega r)^{2} l(r) r \mathrm{~d} r\right. \\
\left.+D_{b} \int_{0}^{R_{r c}-R_{c}}(V-\omega r)^{2} r C_{D b} \mathrm{~d} r\right]
\end{array}
$$

where $r$ is the distance to the rotation axis, $l(r)$ is the width of the cup at position $r, g_{1}(r)$ is the drag coefficient of each section $l(r)$ of the cup, and $V, \omega, R_{c}$, and $R_{r c}$ are the wind speed, rotational speed, cup radius, and cup center rotation radius, respectively. Finally, $D_{b}$ is the diameter of the arm that attaches the cup to the rotor's head and $C_{D b}$ is the drag coefficient of the cross section of that arm (obviously, referred to the diameter $D_{b}$ ). In addition, at position $\alpha=180^{\circ}$, the torque on the cup is defined by the following equation:

$$
\begin{aligned}
M_{2}=\frac{1}{2} \rho & {\left[\int_{R_{r c}-R_{c}}^{R_{r c}+R_{c}} g_{2}(r)(V+\omega r)^{2} l(r) r \mathrm{~d} r\right.} \\
& \left.+D_{b} \int_{0}^{R_{r c}-R_{c}}(V+\omega r)^{2} r C_{D b} \mathrm{~d} r\right]
\end{aligned}
$$

where $g_{2}(r)$ is the drag coefficient of each section $l(r)$ of the cup in the new position (note that torques $M_{1}$ and $M_{2}$ are defined in different rotational directions). For convenience, the new variable $x=r-R_{r c}$ is considered hereinafter. If the classical model is considered, the average aerodynamic torque on a cup in a rotor is characterized by the two positions mentioned $\left(\alpha=0^{\circ}\right.$ and $\left.\alpha=180^{\circ}\right)$. So, as in the equilibrium 
(autorotation) state, this aerodynamic torque on the rotor must counterbalance the friction torque, $M_{f}$. That condition can be expressed as

$$
N_{c}\left(M_{1}-M_{2}\right)-M_{f}=0
$$

where $N_{c}$ is now a proportional constant that depends on the number of cups. In the classical 2-cup model, expression (11), $N_{c}$ stands for the exact number of cups, nevertheless, if friction is taken into account and the model is fitted to experimental results without introducing any coefficient to take into account the aerodynamic simplification $\left(c_{1}\right.$ and $c_{2}$ in expression (11)), it seems more reasonable to consider the ratio between aerodynamic and friction torques related to the number of cups, and proportional to it in a first approximation. In addition, a linear law is considered for the nonconstant drag coefficients:

$$
g_{1}(x)=C_{d 10}\left(1+\delta_{1} \frac{x}{R_{c}}\right) ; \quad g_{2}(x)=C_{d 20}\left(1+\delta_{2} \frac{x}{R_{c}}\right)
$$

where $C_{d 10}$ and $C_{d 20}$ are the average drag coefficients of the cups $\left(C_{D 1}\right.$ and $C_{D 2}$ in (11) and (12)), $x$ is the distance measured from the center of the cup (see Figure 1), and $\delta_{1}$ and $\delta_{2}$ are slope constants of the mentioned linear laws. Finally, a friction torque coefficient, $C_{m f}$, is defined as

$$
C_{m f}=\frac{M_{f}}{(1 / 2) \rho S_{c} R_{r c} C_{d 10} V^{2} N_{c}} .
$$

Taking into account these last expressions, (18) can be rewritten as

$$
\begin{aligned}
& \frac{1}{2} \rho \int_{-R_{c}}^{R_{c}} C_{d 10}\left(1+\delta_{1} \frac{x}{R_{c}}\right)\left[V-\omega\left(R_{r c}+x\right)\right]^{2} \\
& \quad \times 2 R_{c} \sqrt{1-\left(\frac{x}{R_{c}}\right)^{2}}\left(R_{r c}+x\right) \mathrm{d} x \\
& -\frac{1}{2} \rho \int_{-R_{c}}^{R_{c}} C_{d 20}\left(1+\delta_{2} \frac{x}{R_{c}}\right)\left[V-\omega\left(R_{r c}+x\right)\right]^{2} \\
& \quad \times 2 R_{c} \sqrt{1-\left(\frac{x}{R_{c}}\right)^{2}}\left(R_{r c}+x\right) \mathrm{d} x \\
& +\frac{1}{2} \rho D_{b} C_{D b} \int_{0}^{R_{r c}-R_{c}}\left[(V-\omega r)^{2}-(V+\omega r)^{2}\right] r \mathrm{~d} r \\
& -\frac{1}{2} \rho S_{c} R_{r c} C_{d 10} C_{m f}=0 .
\end{aligned}
$$

If the same linear law is considered for both $g_{1}(x)$ and $g_{2}(x)$; that is,

$$
\delta_{1}=\delta_{2}=\delta
$$

and coefficient $k_{D}$ is now defined as

$$
k_{D}=\sqrt{\frac{C_{d 20}}{C_{d 10}}},
$$

then the following expression can be derived from (21):

$$
\begin{aligned}
& \left(1-k_{D}^{2}\right)\left(1+\frac{\delta}{4} r_{r}-\frac{C_{m f}}{1-k_{D}^{2}}\right)-2 \Omega\left(1+k_{D}^{2}\right) \\
& \quad \times\left(1+\frac{\delta}{2} r_{r}+\frac{1}{4} r_{r}^{2}+\frac{\varepsilon}{1+k_{D}^{2}}\right)+\Omega^{2}\left(1-k_{D}^{2}\right) \\
& \quad \times\left(1+\frac{3}{4} \delta r_{r}+\frac{3}{4} r_{r}^{2}+\frac{1}{8} r_{r}^{3}\right)=0,
\end{aligned}
$$

where

$$
\varepsilon=\frac{2}{3 \pi} \frac{D_{b}}{R_{r c}} \frac{C_{D b}}{C_{d 10}} \frac{1}{r_{r}^{2}}\left(1-r_{r}\right)^{3}=\varepsilon_{r} \frac{1}{r_{r}^{2}}\left(1-r_{r}\right)^{3} .
$$

As previously indicated, $r_{r}=R_{c} / R_{r c}$ is the ratio of cup radius to cup center rotation radius in the equations above.

Finally, a simple expression can be obtained:

$$
\Omega^{2}-2 \Omega \gamma(1+a)+(1+b)=0,
$$

where

$$
\begin{aligned}
\gamma & =\frac{1+k_{D}^{2}}{1-k_{D}^{2}}, \\
a & =\frac{1+a_{1}}{1+a_{0}}-1=\frac{a_{1}+a_{0}}{1+a_{0}}, \\
b & =\frac{1+a_{2}}{1+a_{0}}-1=\frac{a_{2}+a_{0}}{1+a_{0}}, \\
a_{0} & =\frac{3}{4} \delta r_{r}+\frac{3}{4} r_{r}^{2}+\frac{1}{8} r_{r}^{3}, \\
a_{1} & =\frac{\delta}{2} r_{r}+\frac{1}{4} r_{r}^{2}+\frac{\varepsilon}{1+k_{D}^{2}}, \\
a_{2} & =\frac{\delta}{4} r_{r}-\frac{C_{m f}}{1+k_{D}^{2}} .
\end{aligned}
$$

It must also be said that expression (26) is dependent on coefficients $\left(a_{0}, a_{1}, a_{2}, a\right.$, and $\left.b\right)$, which are low when compared to 1 . This makes it possible to derive solutions using Taylor series expansions. Also, if friction is considered negligible $\left(C_{m f}=0\right)$, the drag coefficient distributions along the cups are considered constant $(\delta=0)$, and no aerodynamic drag is considered on the cup arms $\left(C_{D b}=0\right)$; expression (26) turns into

$$
\Omega^{2}-2 \Omega \gamma+1=0
$$

and the solutions are

$$
\Omega=+\gamma \pm \sqrt{\gamma^{2}-1}
$$

Obviously, the only logical solution is the one with a negative $\operatorname{sign}(\Omega<1)$ :

$$
\Omega=\Omega_{0}=\frac{1-k_{D}}{1+k_{D}} .
$$

As stated in Section 1, this is the solution for the simpler 2-cup modeling of cup anemometer behavior. 
Going back to (26), if small perturbations are considered (drag distribution on cups, friction, etc.), it is possible to find an approximate asymptotic solution:

$$
\Omega=\Omega_{0}+\Omega_{1},
$$

where $\Omega_{1} \ll \Omega_{0}$. In addition, considering $a, b \ll 1$ as stated above, the following expression can be derived (see Appendix B):

$$
\begin{aligned}
\Omega_{1}= & \frac{\Omega_{0} a \gamma-b / 2}{\Omega_{0}-\gamma} \\
= & \left(\frac{1+k_{D}^{2}}{\left(1+k_{D}\right)^{2}}\left(-\frac{1}{4} \delta r_{r}+\frac{\varepsilon}{1+k_{D}^{2}}\right)\right. \\
& \left.\quad-\frac{1}{2}\left(-\frac{\delta}{2} r_{r}-\frac{C_{m f}}{1-k_{D}^{2}}\right)\right) \times\left(-\frac{2 k_{D}}{1-k_{D}^{2}}\right)^{-1} \\
\cong & -\frac{\delta r_{r}}{4} \Omega_{0}-\frac{1}{2 k_{D}} \Omega_{0} \varepsilon-\frac{1}{4} \frac{C_{m f}}{k_{D}} .
\end{aligned}
$$

Finally, (31) can be expressed as

$$
\Omega=\Omega_{0}-\left[\frac{\delta r_{r}}{4} \Omega_{0}+\frac{1}{2 k_{D}} \Omega_{0} \varepsilon+\frac{1}{4} \frac{C_{m f}}{k_{D}}\right] .
$$

In Figure 5, the exact and approximate solutions for the proposed method ((24) and (33), resp.) are fitted to the experimental results (Table 2), without taking into account the offset of the transfer function; that is, $\Omega=1 / K_{S}$ (see expression (9)). These solutions, $k_{D}=0.656$ and $\delta=-1.8$, were calculated without considering the effect of the rotor arm or friction $\left(\varepsilon=0\right.$ and $\left.C_{m f}=0\right)$. As shown in the figure, there is good agreement between the solutions. Several conclusions can be derived from (32). As expected, the contribution of the rotor arm and friction, $\varepsilon$ and $C_{m f}$, tends to reduce the steady rotational speed, $\Omega$. On the other hand, the fitting to the experimental results reveals a negative value of $\delta$, indicating a higher average aerodynamic load on the closest-to-the-rotating-axis area of the cup. This is a rather surprising result, which could be produced by both unsteady and rotational aerodynamic effects.

In order to analyze anemometer transfer function (3) using the model developed to introduce the effects of the rotor arms, friction, and the aforementioned "inverse" distribution of the aerodynamic load on the cup, the anemometer factor, $K$, must be expressed as a function of $1 / \Omega$ :

$$
\begin{aligned}
\frac{V}{\omega R_{r c}}= & \frac{1}{\Omega}=\frac{1}{\Omega_{0}+\Omega_{1}} \cong \frac{1}{\Omega_{0}} \frac{1}{1+\Omega_{1} / \Omega_{0}} \cong \frac{1}{\Omega_{0}}\left(1-\frac{\Omega_{1}}{\Omega_{0}}\right) \\
= & \frac{1}{\Omega_{0}}-\frac{1}{\Omega_{0}^{2}} \Omega_{1}=\frac{1}{\Omega_{0}}+\frac{1}{\Omega_{0}^{2}} \\
& \times\left[\frac{\delta r_{r}}{4} \Omega_{0}+\frac{1}{2 k_{D}} \Omega_{0} \varepsilon+\frac{1}{4 k_{D}} C_{m f}\right] \\
= & \frac{1}{\Omega_{0}}\left(1+\frac{1}{4} \delta r_{r}+\frac{1}{2 k_{D}} \varepsilon+\frac{1}{4 k_{D}} \frac{C_{m f}}{\Omega_{0}}\right),
\end{aligned}
$$

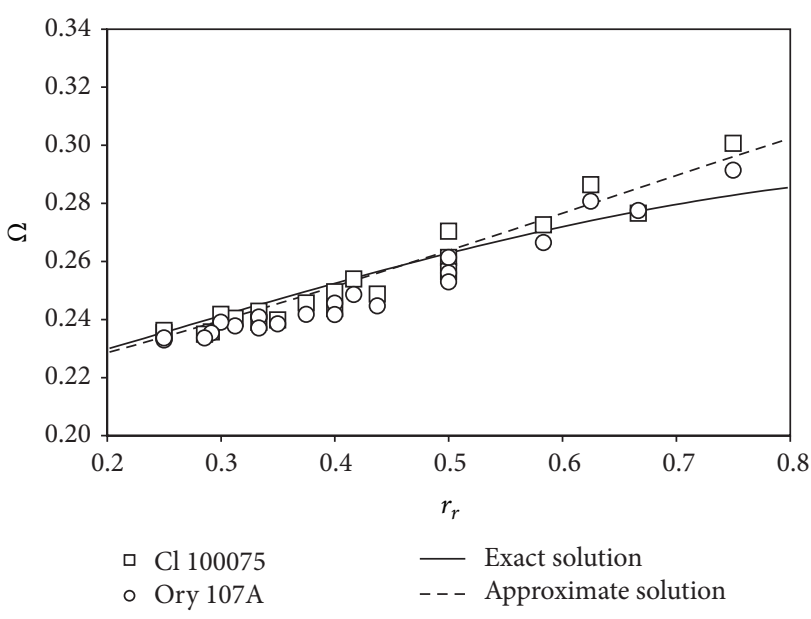

FIgURE 5: Parameter $\Omega$ estimated with the results from the calibrations performed on the Climatronics 100075 and Ornytion 107A anemometers, $\Omega=1 / K_{S}$ (see also Figure 2). The graph also includes the results from the exact and approximate solutions for the proposed analytical model ((24) and (33), resp.), fitted to the experimental data.

and then

$$
\begin{aligned}
V= & \omega R_{r c} \frac{1}{\Omega}=\omega R_{r c} \frac{1}{\Omega_{0}}\left(1+\frac{1}{4} \delta r_{r}+\frac{1}{2 k_{D}} \mathcal{E}+\frac{1}{4 k_{D} \Omega_{0}} C_{m f}\right) \\
= & \omega R_{r c} \frac{1}{\Omega_{0}}\left[1+\frac{1}{4} \delta r_{r}+\frac{1}{2 k_{D}} \varepsilon_{r} \frac{1}{r_{r}^{2}}\left(1-r_{r}\right)^{3}\right] \\
& +\frac{1}{4 k_{D} \Omega_{0}^{2}} \omega R_{r c} C_{m f} .
\end{aligned}
$$

The first term in the above equation directly affects the first term in transfer function (3), $A_{r} \omega$, and can be divided into three other terms. The first,

$$
\omega R_{r c} \frac{1}{\Omega_{0}}
$$

only depends on the cup aerodynamics and not on the slight effects considered. The second one,

$$
\omega R_{r c} \frac{1}{\Omega_{0}} \frac{1}{4} \delta r_{r},
$$

implies a correction of the slope, linear with $r_{r}$, that would be included in the second term in expression (10), respecting the negative sign as $\delta<0$. Finally, the third term,

$$
\omega R_{r c} \frac{1}{\Omega_{0}} \frac{1}{2 k_{D}} \varepsilon_{r}\left(\frac{1}{r_{r}^{2}}-\frac{3}{r_{r}}+3-r_{r}\right),
$$

can also be separated into three different contributions to the slope of the transfer function:

(1) one correction not dependent on $r_{r}$

$$
\left(\frac{3}{2}\right) \frac{\varepsilon_{r}}{k_{D}}
$$


(2) one correction linear with $r_{r}$, which also respects the negative sign in the second term in expression (10)

$$
-\left(\frac{1}{2}\right) \frac{\varepsilon_{r}}{k_{D}} r_{r}
$$

(3) and, finally, a nonlinear term

$$
\left(\frac{1}{2}\right) \frac{\varepsilon_{r}}{k_{D}}\left(\frac{1}{r_{r}^{2}}-\frac{3}{r_{r}}\right) .
$$

With regard to the second term in (35), it represents a friction velocity term, $V_{f}$, which can be expressed as

$$
\begin{aligned}
V_{f} & =\frac{\omega R_{r c}}{4 k_{D} \Omega_{0}^{2}}\left(\frac{M_{f}}{(1 / 2) \rho S_{c} R_{r} C_{d 10} V^{2}}\right) \\
& =\frac{1}{4 k_{D} \Omega_{0}} \frac{M_{f}}{(1 / 2) \rho S_{c} R_{r} C_{d 10} V} .
\end{aligned}
$$

If the second-order polynomial approximation for the friction torque mentioned in Section 1 is considered:

$$
M_{f}=M_{f 0}+M_{f 1} \omega+M_{f 2} \omega^{2},
$$

then (42) turns into

$$
V_{f}=\frac{1}{4 k_{D} \rho S_{c} C_{d 10}}\left(\frac{M_{f 0}}{\omega R_{r c}^{2}}+\frac{M_{f 1}}{R_{r c}^{2}}+\frac{M_{f 2}}{R_{r c}^{2}} \omega\right),
$$

where the first term,

$$
\frac{M_{f 0}}{\omega R_{r c}^{2}},
$$

indicates the deviation from the ideal velocity (36) at low rotational speeds. This effect is mentioned in Section 1 , where the non-linear behavior of anemometer constant $K$ at low wind speeds is described. The second term,

$$
\frac{M_{f 1}}{R_{r c}^{2}}
$$

involves a contribution that does not depend on $\omega$, so it represents the offset constant, $B$, in transfer function (3). Finally, the third term,

$$
\frac{M_{f 2}}{R_{r c}^{2}} \omega
$$

represents a contribution to transfer function slope $A_{r}$.

From expression (42), it can also be assumed that the friction term, $V_{f}$, is inversely proportional to the cup surface, $S_{c}$, meaning that bigger cups would be translated into a lower friction term. Nevertheless, it must be taken into account that bigger cups also experience greater lateral forces on the anemometer rotor shaft, increasing the friction.
As mentioned, the results included in Table 2 summarize the results from [21]. Bearing in mind these results (see expressions (3) to (7)), it is possible to derive the following equation:

$$
\begin{aligned}
V-B & =\left(\frac{\mathrm{d} A_{r}}{\mathrm{~d} R_{r}} R_{r}+A_{r 0}\right) f=2 \pi K_{A} R_{r c} f+2 \pi K_{c} R_{c} f \\
& =K_{A} R_{r c} \omega+K_{c} R_{c} \omega,
\end{aligned}
$$

where

$$
K_{A}=\frac{1}{2 \pi} \frac{\mathrm{d} A_{r}}{\mathrm{~d} R_{r c}}
$$

is the contribution to the anemometer factor that depends on the cup center rotation radius, $R_{r c}$, and:

$$
K_{c}=\frac{1}{2 \pi R_{c}} A_{r 0}
$$

is the contribution to the anemometer factor that does not depend on the cup center rotation radius but on the cup radius, $R_{c}$. Both coefficients, $K_{A}$ and $K_{c}$, are dimensionless and can be related to the anemometer factor defined in expression (9) through the following equation:

$$
K_{S}=K_{A}+K_{c} r_{r} .
$$

If we compare expression (48) to the same expression obtained from the theoretical model (35), neglecting the effect of rotor arms or friction $\left(\varepsilon=C_{m f}=0\right)$, that is,

$$
V=\frac{\omega}{\Omega_{0}} R_{r c}\left(1+\frac{1}{4} \delta r_{r}\right)=\frac{\omega R_{r c}}{\Omega_{0}}+\frac{\omega R_{c}}{\Omega_{0}} \frac{\delta}{4},
$$

the two terms of the aforementioned (48) can be explained from a theoretical basis. First, the slope of the anemometer calibration curve (a transfer function based on the rotation frequency; that is, expression (3) instead of expression (2)), has one term, $K_{A} R_{r c} \omega$, proportional to the cup center rotation radius, $R_{r c}$, with the proportionality constant $K_{A}=1 / \Omega_{0}$. Second, the last term of the aforementioned anemometer transfer function slope, $K_{c} R_{c} \omega$, which does not depend on $R_{r c}$, depends on both the load (pressure) distribution along the cups, $\delta$, and the cup radius, $R_{c}$. It should be underlined that this second term in the equation of the anemometer factor only appears in the theoretical model if the "inverse" force distribution along the cup is considered.

Comparing expressions (51) and (52) leads to

$$
\frac{1}{4} \frac{\delta}{\Omega_{0}} \cong K_{c}=\frac{A_{r 0}}{2 \pi R_{c}} .
$$

Finally, combining expressions (49) and (53) with the above equation it is possible to rewrite expression (51) in terms of the mentioned ratio of cup radius to cup center rotation radius, $r_{r}=R_{c} / R_{r c}$, as

$$
K_{S}=\frac{1}{2 \pi}\left[\frac{\mathrm{d} A_{r}}{\mathrm{~d} R_{r c}}+\frac{\pi}{2} \frac{\delta}{\Omega_{0}} r_{r}\right],
$$


TABLE 3: Parameters $k_{D}$ and $\delta$ from the fittings of the proposed analytical model (with $\varepsilon=C_{m f}=0$, see expression (24)), to the testing results (see Figure 6). The table also includes the slope, $\mathrm{d} K_{S} / \mathrm{d} r_{r}$, the offset, $K_{S 0}$, and determination coefficient $R^{2}$ of the linear fittings for each case.

\begin{tabular}{|c|c|c|c|c|c|}
\hline$R_{\mathrm{rc}}[\mathrm{mm}]$ & $k_{D}$ & $\delta$ & $K_{S 0}\left(=K_{A}\right)$ & $\mathrm{d} K_{S} / \mathrm{d} r_{r}\left(=K_{c}\right)$ & $R^{2}$ \\
\hline \multicolumn{6}{|c|}{ Climatronics 100075} \\
\hline 40 & 0.6450 & -1.7618 & 4.4353 & -1.4874 & 0.9961 \\
\hline 60 & 0.6505 & -1.6958 & 4.5983 & -1.5287 & 0.9747 \\
\hline 80 & 0.6481 & -1.5494 & 4.5779 & -1.3297 & 0.9758 \\
\hline 100 & 0.6372 & -1.1801 & 4.4256 & -0.8035 & 0.6975 \\
\hline 120 & 0.6343 & -0.9889 & 4.3904 & -0.5810 & 0.6002 \\
\hline \multicolumn{6}{|c|}{ Ornytion 107A } \\
\hline 40 & 0.6544 & -1.7731 & 4.5936 & -1.5784 & 0.9635 \\
\hline 60 & 0.6570 & -1.7327 & 4.7082 & -1.6406 & 0.9972 \\
\hline 80 & 0.6511 & -1.5238 & 4.6200 & -1.2895 & 0.9521 \\
\hline 100 & 0.6418 & -1.2409 & 4.4985 & -0.9116 & 0.8076 \\
\hline 120 & 0.6391 & -1.0947 & 4.4661 & -0.7407 & 0.9999 \\
\hline
\end{tabular}

TABLE 4: Fitting coefficients of the linear approximation to parameters $K_{A}$ and $K_{c}$ (see expressions (55)) from the Climatronics 100075 and Ornytion 107A anemometer testing campaign, as a function of $R_{r c}$ for $R_{r c}>60 \mathrm{~mm}$. See also Figure 7 .

\begin{tabular}{lcccc}
\hline Anemometer & $K_{A 0}$ & $K_{A S}\left[\mathrm{~mm}^{-1}\right]$ & $K_{c 0}$ & $K_{c S}\left[\mathrm{~mm}^{-1}\right]$ \\
\hline Climatronics 100075 & 4.8473 & -0.0039 & -2.5769 & 0.0168 \\
Ornytion 107A & 4.9548 & -0.0042 & -2.5305 & 0.0154 \\
\hline
\end{tabular}

which, taking into account the negative value of coefficient $\delta$, results in an equation very similar to the one derived from the experimental results (10). Nevertheless, it must also be noted that both terms in expression (10) include the slight effects of rotor arms and friction, which are not considered in the above equation.

\section{Results and Discussion}

In Figure 6, anemometer factor $K_{S}$, obtained from the calibrations performed on the anemometers used in the testing campaign, is shown as a function of the parameter $r_{r}$, for rotors with the same cup center rotation radius, $R_{r c}$. The figure also compares these experimental results to those from the proposed analytical model, without taking into account the effect of rotor arms or friction $\left(\varepsilon=C_{m f}=0\right)$. In each case, the complete expression from the analytical model (24) is fitted by adjusting both $k_{D}$ and $\delta$. Table 3 includes the values of these parameters for each case, along with the slope, $\mathrm{d} K_{S} / \mathrm{d} r_{r}$, and offset, $K_{S 0}$, of the linear fittings and the corresponding determination coefficient, $R^{2}$. Obviously, $\mathrm{d} K_{S} / \mathrm{d} r_{r}=K_{c}$ and $K_{S 0}=K_{A}$, from expression (51).

Good agreement between the proposed model and the testing results is observed in Figure 6; in other words, the effect of parameter $r_{r}$ is correctly reflected by the model. However, it is also fair to say that greater differences between the model and the experimental results are observed in the figure for higher values of $R_{r c}$. This dispersion of the testing results could be explained by the fact that a longer cup center rotation radius, $R_{r c}$, lowers the rotation speed, making the rotation movement less constant and more influenced by the third harmonic term $[4,136]$ (the rotation speed of a cup anemometer can be decomposed into different harmonic terms using the Fourier expansion: $\omega(t)=\omega_{0}+\omega_{1} \sin \left(\omega_{0} t+\right.$ $\left.\varphi_{1}\right)+\omega_{2} \sin \left(2 \omega_{0} t+\varphi_{2}\right)+\omega_{3} \sin \left(3 \omega_{0} t+\varphi_{3}\right) \ldots$ Leaving aside the average term, $\omega_{0}$, the third harmonic term, $\omega_{3}$, is the most important term of the expansion in normal circumstances due to the 3-cup rotor shape).

To return to the linear fittings in Table 3, taking into account the high values of determination coefficient $R^{2}$, it seems that the linear approximation previously derived (51) reflects the anemometer behavior quite well. It is also possible to observe the variation of both coefficients, $K_{A}$ and $K_{c}$, as a function of $R_{r c}$, which is plotted in Figure 7. For both anemometers, Climatronics 100075 and Ornytion 107A, these coefficients show approximate linear behavior for $R_{r c}>$ $60 \mathrm{~mm}$ :

$$
\begin{gathered}
K_{A}=K_{A 0}+K_{A S} R_{r c}, \\
K_{c}=K_{c 0}+K_{c S} R_{r c} .
\end{gathered}
$$

For lower cup center rotation radius values, $R_{r c}<60 \mathrm{~mm}$, the tendency of both coefficients, $K_{A}$ and $K_{c}$, to decrease the anemometer factor as a function of $R_{r c}$ is alleviated, probably due to cup-wake interaction. Table 4 includes the coefficients of the aforementioned linear fitting to $K_{A}$ and $K_{c}$ for $R_{r c}>$ $60 \mathrm{~mm}$ (expressions (55)). The following conclusions can be reached from these fittings.

(i) The behavior of coefficient $K_{c}$ is very similar for both anemometers, an average expression being: $K_{c}=$ $-2.55+0.0161 R_{r c}$. $\left(R_{r c}\right.$ expressed in $\left.\mathrm{mm}\right)$. This parameter seems to depend only on the rotor shape (cups size and rotor diameter) and not on the anemometer shape (anemometer body). 


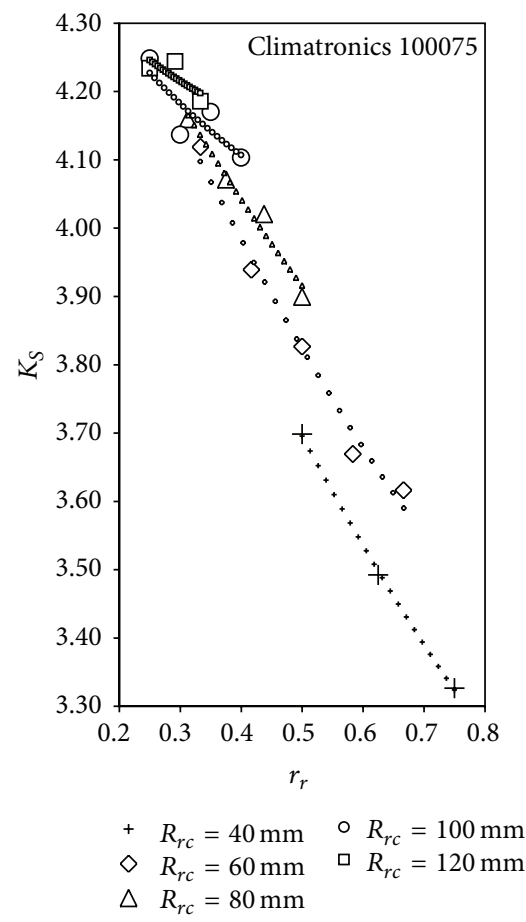

(a)

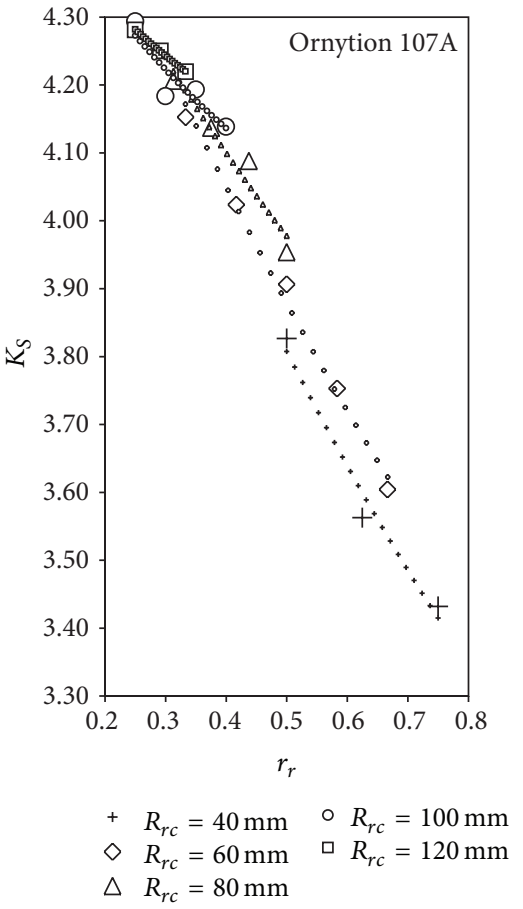

(b)

FIGURE 6: Anemometer factor, $K_{S}$, from the calibrations performed on the Climatronics 100075 and Ornytion 107A as a function of parameter $r_{r}$, for rotors with the same cup center rotation radius, $R_{r c}$. The small symbols correspond to the analytical model (expression (24)), fitted to the experimental results. See also Table 3.

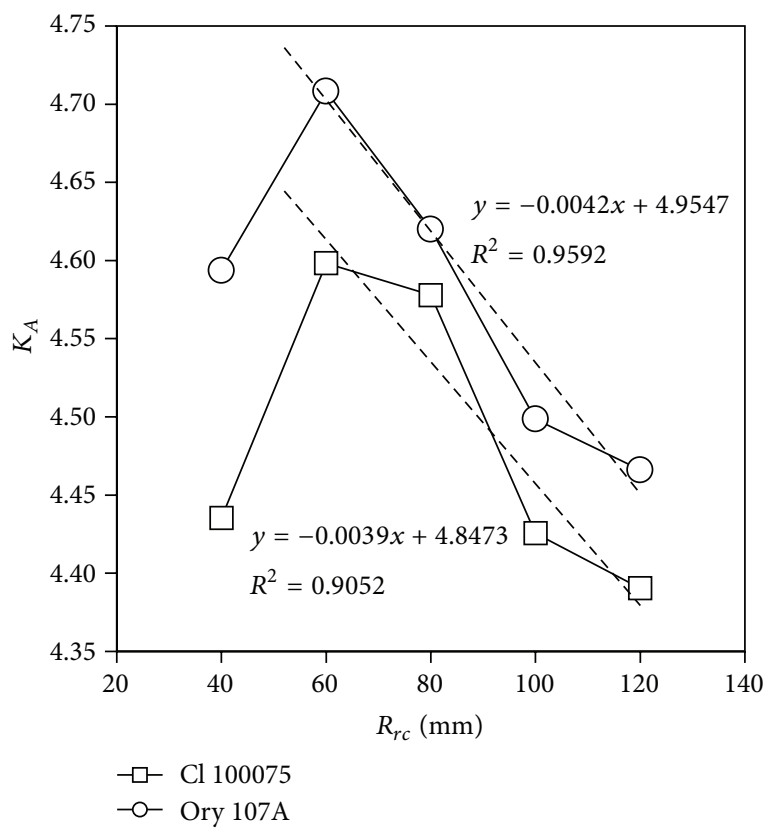

(a)

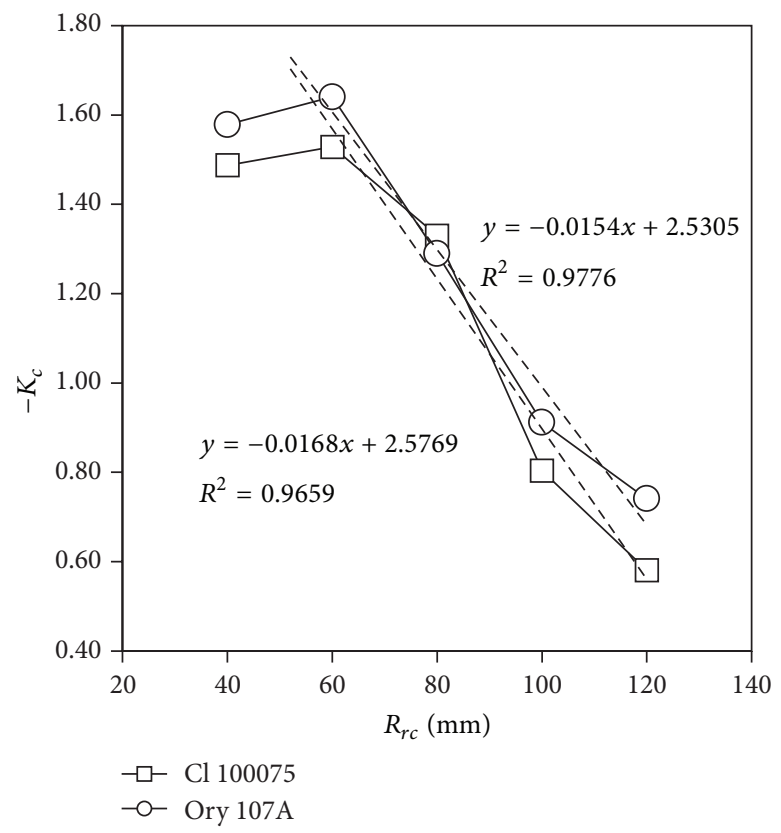

(b)

Figure 7: Coefficients $K_{A}$ and $K_{c}$, plotted as a function of $R_{r c}$, for both anemometers, Climatronics 100075 and Ornytion 107A. The linear fittings to the data have been included in the graphs for $R_{r c} \geq 60 \mathrm{~mm}$ (in other words, they were calculated excluding the point $R_{r c}=40 \mathrm{~mm}$ ). 
(ii) The linear fittings to parameter $K_{A}$ show similar values for the slope, $K_{A S}$, but different values for the offset, $K_{A 0}$. This difference could be explained by different friction on the shaft/bearings system or a different anemometer shape ("neck" thickness).

From expressions (51) and (55) it is possible to obtain, in combination with the anemometer factor equation,

$$
K_{S}=\frac{V-B}{\omega R_{r c}}=\left(K_{A 0}+K_{A S} R_{r c}\right)+\left(K_{c 0}+K_{c S} R_{r c}\right) r_{r},
$$

a new expression for wind speed,

$$
V=\left[K_{A 0}+K_{A S} R_{r c}+K_{c S} R_{c}\right] R_{r c} \omega+K_{c 0} R_{c} \omega+B,
$$

that is, an expression indicating a term related to the anemometer transfer function slope, $K_{c 0} R_{c}$, which does not depend on $R_{r c}$. The effect of this term was experimentally observed [21]; see expression (6).

To return to (53), it is possible to estimate the gradient along the cup of the normal-to-the-cup aerodynamic force, $\delta$ (see expressions (19) and (22)),

$$
\delta \cong \frac{2}{\pi} \Omega_{0} \frac{A_{r 0}}{R_{c}} .
$$

Figure 8 shows coefficient $A_{r 0}$ as a function of the anemometer cup radius, $R_{c}$. Considering an average value between $A_{r 0} / R_{c}=-12.2$ (Climatronics 100075) and $A_{r 0} / R_{c}=-10.9$ (Ornytion 107A), the above equation can be rewritten as

$$
\delta \cong-7.38 \frac{1-k_{D}}{1+k_{D}} .
$$

The above equation clearly indicates the aforementioned "inverse" aerodynamic load distribution on the anemometer cups. In other words, the aerodynamic load on the rotating cup is higher in the area closest to the rotating axis. This effect, which could be attributed to local changes in wind direction along the cup, to the effect of rotating flow on the pressure distribution along the cup, or to wake interaction, should not be neglected in the development of new models for studying cup anemometers.

In a previous paper [21], the offset of the transfer function (coefficient $B$ in expressions (2) and (3)) was experimentally fitted to the expression, depending on the cup center rotation radius, $R_{r c}$, and the front area of the cups, $S_{c}$ (see (7)). Taking that expression into account, offset $B$ depends linearly on $R_{r c}$. Figure 9 shows coefficient $B$ for the calibrations performed (see Table 2) as a function of the cup center rotation radius, $R_{r c}$, for each cup radius, $R_{c}$. Linear fittings to the data are also shown in the graphs (the coefficients for these fittings, $\mathrm{d} B / \mathrm{d} R_{r c}$ and $B_{0}$, are included in Table 2 ). The linear trend mentioned earlier is shown in the graphs, although it is much clearer in the case of the Ornytion 107A. This could be explained by the different effects of aging or wear and tear, on both anemometers. In the testing campaign considered in this paper, the Ornytion 107A was new, whereas the Climatronics 100075 had been used for internal procedures at the IDR for several years (some degree of degradation regarding this

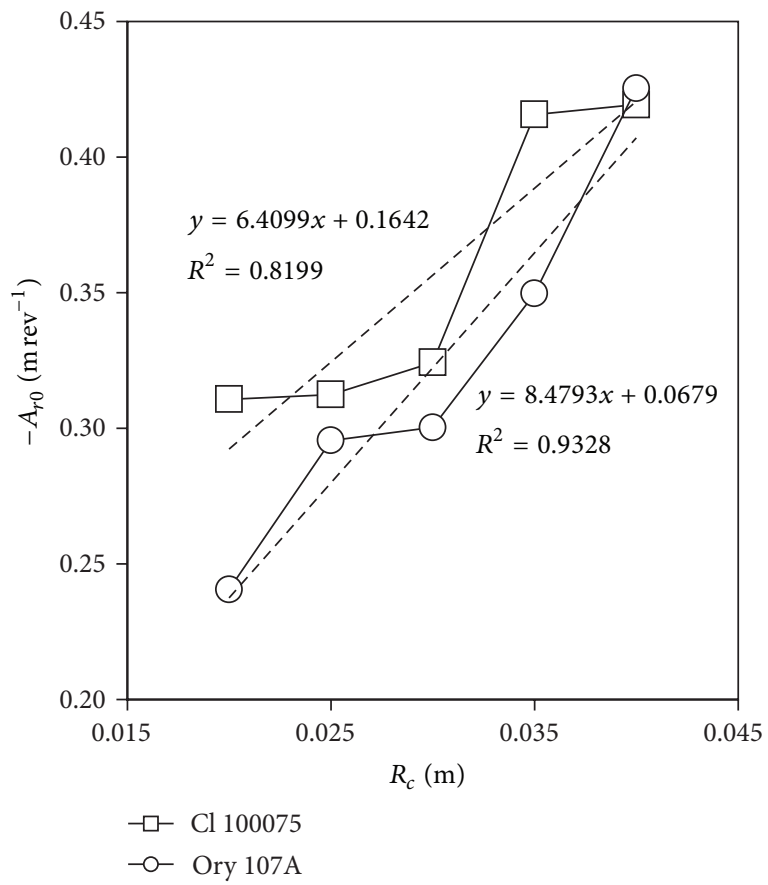

Figure 8: Constant term of the slope for calibration coefficient $A_{r 0}$ (see expression (4)) from the testing results, as a function of anemometer cup radius, $R_{c}$. Linear fittings have been added to the graph.

anemometer was previously illustrated in [82]). Another effect observed in the curves corresponding to $R_{c}=25$ and $R_{c}=30$ for the Climatronics 100075 is a deviation from the linear trend for lower values of $R_{r c}$. This suggests an interaction between the cup and the wake generated at the anemometer's "neck." This effect is not observed in the graph for the Ornytion 107A, probably because this anemometer has a thinner "neck," which also produces a thinner wake. Finally, a decrease in the slope, $\mathrm{d} B / \mathrm{d} R_{r c}$, along with the cup radius, $R_{c}$, can be observed in Figure 9.

\section{Conclusions}

In this study, cup anemometer response was analyzed using the 2-cup analytical model. The model was fitted to experimental data from 42 calibrations performed on two different cup anemometers (Climatronics 10075 and Ornytion 107A), equipped with 21 different cup rotors (conical cups, with varying cup sizes and distances to the rotation axis). The major conclusions resulting from this study are as follows.

(i) The anemometer factor, $K_{S}$, for cup anemometers equipped with conical cups depends linearly on the shape parameter $r_{r}$ (the ratio of the cup radius to the cup center rotation radius, $\left.r_{r}=R_{c} / R_{r c}\right), K_{S}=$ $K_{A}+K_{c} r_{r}$, within the range studied (from $r_{r}=0.25$ to $r_{r}=0.75$ ). The slope of this linear behavior, $K_{c}$, seems to depend only on the rotor shape but not on the anemometer body (for the anemometers tested).

(ii) The results indicate that the aerodynamic force distribution along the rotating cups is not uniform, as the calculated aerodynamic force is higher closer to 


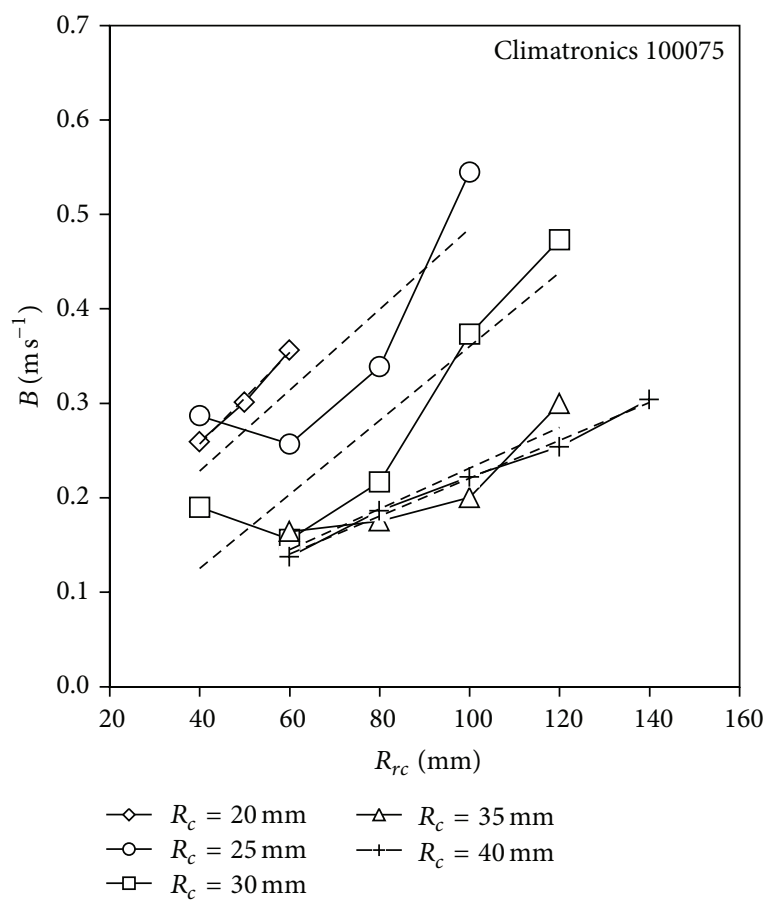

(a)

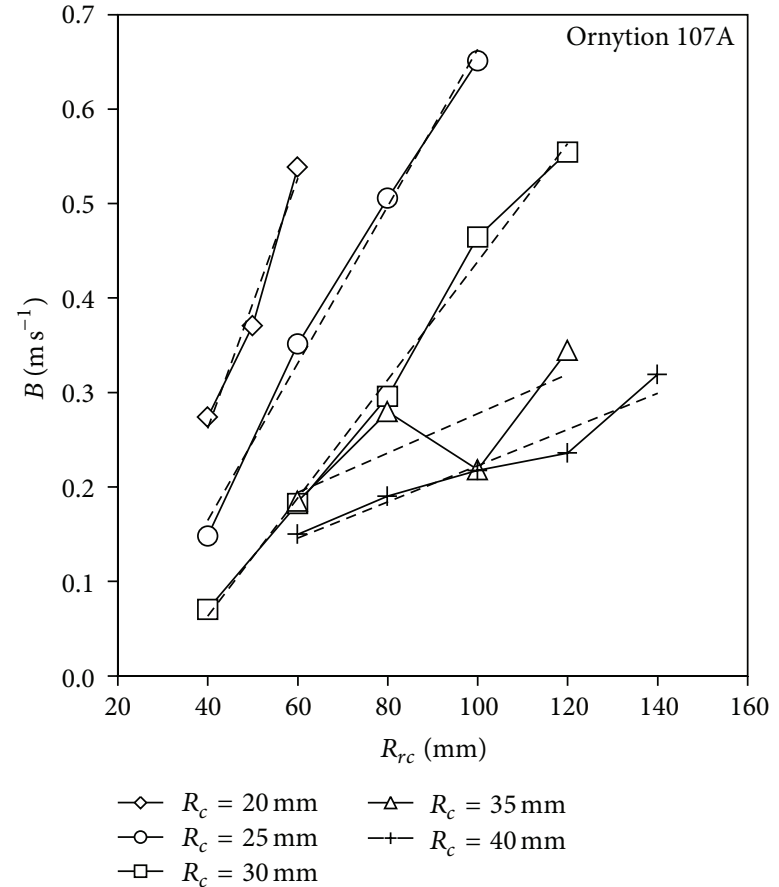

(b)

Figure 9: Coefficient $B$ for the calibrations performed (see Table 2) on the Climatronics 100075 and the Ornytion 107A anemometers, shown as a function of the cup center rotation radius, $R_{r c}$, for each cup radius, $R_{c}$. Linear fittings to the data are also shown in the graphs (the coefficients of these fittings, $\mathrm{d} B / \mathrm{d} R_{r c}$ and $B_{0}$, are included in Table 2).

the rotating axis, which explains the linear correction term $K_{c} r_{r}$ to the anemometer factor.

(iii) The classical 2-cup analytical model modified with the nonconstant force distribution along the rotating cup of the anemometer seems to be accuratelinebreak enough for studying the complex aerodynamics effects involved in the rotor performance.

\section{Appendices}

\section{A.}

Anemometer calibrations are performed in the S4 wind tunnel at the IDR/UPM Institute. This is an open-circuit wind tunnel with a closed test section measuring 0.9 by $0.9 \mathrm{~m}$. It is served by four $7.5 \mathrm{~kW}$ fans with a flow uniformity under $0.2 \%$ in the testing area. The wind speed in the testing chamber is measured by Airflow 0.48 Pitot tube connected to a Druck LPM 9481 high-precision pressure transducer, with the electrical signal from the pressure transducer measured by a Keithley 2000 digital multimeter. Temperature and humidity sensors (Vaisala PTU 200 and Vaisala HMP45D) are used to determine the air density value. The rotation frequency of the anemometer is measured with an Agilent 53131A universal counter. Another digital multimeter is used to measure the voltage or current output from the anemometer when required.

An example of the calibrations performed on this wind tunnel is included in Figure 10. The wind speed measured by the wind tunnel instruments, $V$, is plotted in comparison

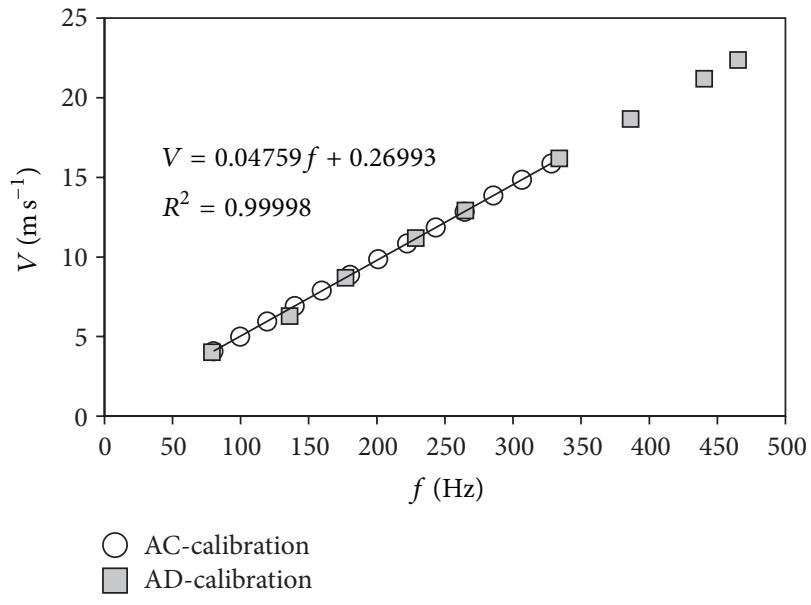

FIGURE 10: Results from two calibrations performed at the S4 anemometer calibration wind tunnel of the IDR/UPM Institute, on the same cup anemometer (Thies Clima 4.3350) following two different procedures, $\mathrm{AC}$ and $\mathrm{AD}$. AC calibrations follow strictly MEASNET procedure (wind speeds ranging from $4 \mathrm{~m} \mathrm{~s}^{-1}$ to $16 \mathrm{~m} \mathrm{~s}^{-1}$, and 13 measurement points are taken), whereas $\mathrm{AD}$ calibrations are carried out over a broader wind speed range (from $4 \mathrm{~m} \mathrm{~s}^{-1}$ to $23 \mathrm{~m} \mathrm{~s}^{-1}$ ) and less measurement points are taken (9 instead of 13).

to the anemometer's frequency output, $f$. The calibration curve (i.e., the linear transfer function) corresponding to the AC calibration is plotted in the aforementioned figure (its mathematical expression is also included). The uncertainty levels of the calibrations performed at the S4 calibration wind 
tunnel are specified following the ISO/IEC 17025 standard [137], these levels being $0.1 \mathrm{~m} \mathrm{~s}^{-1}$ for wind speeds from $4 \mathrm{~m} \mathrm{~s}^{-1}$ to $10 \mathrm{~m} \mathrm{~s}^{-1}$ and $0.01 \mathrm{~V} \mathrm{~m} \mathrm{~s}^{-1}$ for wind speeds, $V$, from $10 \mathrm{~m} \mathrm{~s}^{-1}$ to $23 \mathrm{~m} \mathrm{~s}^{-1}$.

\section{B.}

The aim of this Appendix is to find the roots of equation:

$$
\Omega^{2}-2 \Omega \gamma(1+a)+1+b=0
$$

in the case $a, b \ll 1$.

If the following perturbation solution is assumed:

$$
\Omega=\Omega_{0}+\Omega_{1} ; \quad \Omega_{1} \ll \Omega_{0},
$$

then

$$
\Omega_{0}^{2}+2 \Omega_{0} \Omega_{1}+\Omega_{1}^{2}-2 \gamma\left(\Omega_{0}+\Omega_{1}\right)(1+a)+1+b=0 .
$$

The solution is as follows, if $\Omega_{1}=a=b=0$ :

$$
\Omega_{0}^{2}-2 \gamma \Omega_{0}+1=0 \text {, }
$$

where

$$
\Omega_{0}=\gamma-\sqrt{\gamma^{2}-1}=\frac{1-k_{D}}{1+k_{D}} .
$$

If (B.4) is subtracted from (B.3), taking into account $\Omega_{1}^{2} \ll 1$, the following expression is obtained:

$$
2 \Omega_{1}\left[\Omega_{0}-\gamma(1+a)\right]-2 \Omega_{0} a \gamma+b=0
$$

and then

$$
\Omega_{1}=\frac{1}{2} \frac{2 \Omega_{0} a \gamma-b}{\Omega_{0}-\gamma}=\frac{\Omega_{0} a \gamma-b / 2}{\Omega_{0}-\gamma}
$$

where

$$
\Omega_{0}-\gamma=-4 \frac{k_{D}}{1-k_{D}^{2}} .
$$

Once the problem has been linearized, correction $\Omega_{1}$ depends on perturbations $a$ and $b$.

\section{Conflict of Interests}

The authors declare that there is no conflict of interests regarding the publication of this paper.

\section{Acknowledgments}

The authors are indebted to Enrique Vega, Alejandro Martínez, Encarnación Meseguer, Luis García, and Eduardo Cortés for the help regarding the testing campaign and, more generally, all the experimental work carried out. The authors are grateful to Tania Tate for her kind help on improving the style of the text. Prof. Pindado and the other coauthors are truly indebted to Luis Gómez, Eva Díaz, Javier Medel, Clarisa Buendía, and the rest of the staff of the Library at the Aeronautics and Space Engineering School (Escuela de Ingeniería Aeronáutica y del Espacio) of the Polytechnic University of Madrid (Universidad Politécnica de Madrid), for their constant support to the research carried out regarding cup anemometer performances.

\section{References}

[1] M. A. Lackner, A. L. Rogers, and J. F. Manwell, "Uncertainty analysis in wind resource assessment and wind energy production estimation," in Proceedings of the 45th AIAA Aerospace Sciences Meeting, pp. 1-16, AAIA, January 2007.

[2] R. V. Coquilla, J. Obermeier, and B. R. White, "Calibration procedures and uncertainty in wind power anemometers," Wind Engineering, vol. 31, no. 5, pp. 303-316, 2007.

[3] L. Kristensen, “Can a cup anemometer 'underspeed'? A heretical question," Boundary-Layer Meteorology, vol. 103, no. 1, pp. 163$172,2002$.

[4] S. Pindado, J. Cubas, and A. Sanz-Andrés, "Aerodynamic analysis of cup anemometers performance: the stationary harmonic response," The Scientific World Journal, vol. 2013, Article ID 197325, 11 pages, 2013.

[5] International Electrotechnical Commision, International Standard IEC-61400-12-1. Wind Turbines. Part 12-1: Power Performance Measurements of Electricity Producing Wind Turbines, 2005-12, 1st edition, 2005.

[6] A. Albers and H. Klug, "Open field cup anemometry," DEWI Magazin, vol. 19, pp. 53-58, 2001.

[7] A. Albers, H. Klug, and D. Westermann, "Outdoor comparison of cup anemometers," DEWI Magazin, vol. 17, pp. 5-15, 2000.

[8] J.-Å. Dahlberg, J. Gustavsson, G. Ronsten, T. F. Pedersen, U. S. Paulsen, and D. Westermann, Development of a Standardised Cup Anemometer suited to Wind Energy Applications-(Classcup), 2001.

[9] J.-Å. Dahlberg, T. F. Pedersen, and P. Busche, "ACCUWINDmethods for classification of cup anemometers," Tech. Rep., Risø-R-1555(EN), Roskilde, Denmark, 2006.

[10] T. F. Pedersen, "Development of a classification system for cup anemometers-CLASSCUP," Tech. Rep., Risø-R-1348(EN), Roskilde, Denmark, 2003.

[11] E. I. Kaganov and A. M. Yaglom, "Errors in wind-speed measurements by rotation anemometers," Boundary-Layer Meteorology, vol. 10, no. 1, pp. 15-34, 1976.

[12] Y. P. Solov'ev, A. I. Korovushkin, and Y. N. Toloknov, "Characteristics of a cup anemometer and a procedure of measuring the wind velocity," Physical Oceanography, vol. 14, no. 3, pp. 173-186, 2004.

[13] J. C. Wyngaard, J. T. Bauman, and R. A. Lynch, "Cup anemometer dynamics," Flow: Its Measurement and Control in Science and Industry, vol. 1, pp. 701-708, 1974.

[14] J. C. Wyngaard, "Cup, propeller, vane, and sonic anemometers in turbulence research," Annual Review of Fluid Mechanics, vol. 13, pp. 399-423, 1981.

[15] P. Hyson, "Cup anemometer response to fluctuating wind speeds," Journal of Applied Meteorology, vol. 11, no. 5, pp. 843848, 1972.

[16] P. A. Coppin, "An examination of cup anemometer overspeeding," Meteorologische Rundschau, vol. 35, pp. 1-11, 1982.

[17] S. Chang and P. Frenzen, "Further consideration of Hayashi's 'Dynamic response of a cup anemometer,' Journal of Atmospheric and Oceanic Technology, vol. 7, no. 1, pp. 184-186, 1990.

[18] N. E. Busch and L. Kristensen, "Cup anemometer overspeeding," Journal of Applied Meteorology, vol. 15, pp. 1328-1332, 1976.

[19] L. Kristensen, "Cup anemometer behavior in turbulent environments," Journal of Atmospheric and Oceanic Technology, vol. 15, no. 1, pp. 5-17, 1998. 
[20] S. Pindado, E. Vega, A. Martínez, E. Meseguer, S. Franchini, and I. P. Sarasola, "Analysis of calibration results from cup and propeller anemometers. Influence on wind turbine Annual Energy Production (AEP) calculations," Wind Energy, vol. 14, no. 1, pp. 119-132, 2011.

[21] S. Pindado, J. Pérez, and S. Avila-Sanchez, "On cup anemometer rotor aerodynamics," Sensors, vol. 12, no. 5, pp. 6198-6217, 2012.

[22] S. Pindado, I. Pérez, and M. Aguado, "Fourier analysis of the aerodynamic behavior of cup anemometers," Measurement Science and Technology, vol. 24, no. 6, Article ID 065802, 2013.

[23] S. Ramachandran, "A theoretical study of cup and vane anemometers," Quarterly Journal of the Royal Meteorological Society, vol. 95, pp. 163-180, 1969.

[24] J. Kondo, G. I. Naito, and Y. Fujinawa, "Response of cup anemometer in turbulence," Journal of the Meteorological Society of Japan, vol. 49, pp. 63-74, 1971.

[25] MEASNET, Anemometer Calibration Procedure, Version 2, 2009.

[26] MEASNET, Cup Anemometer Calibration Procedure, Version 1, 1997.

[27] M. J. Brevoort and U. T. Joyner, "Experimental investigation of the Robinson-type cup anemometer," NACA TN-513, 1935.

[28] O. Schrenk, "Über die trägheitsfehler des schalenkreuz-anemometers bei schwankender windstärke," Zeitschrift für Technische Physik, vol. 10, pp. 57-66, 1929.

[29] H.-J. Winkel, M. Paschen, and M. Jensch, "Investigations of a cup anemometer in oblique flow for measurement of wind velocity in offshore installations in the field of aquaculture," in Proceedings of the 26th International Conference on Offshore Mechanics and Arctic Engineering (OMAE '07), pp. 715-720, June 2007.

[30] M. Potsdam, L. Cicolani, B. Gassaway, and D. Mattle, "Aerodynamic analysis and flight simulation of an anemometer for rotational stabilization of a helicopter slung load," in Proceedings of the 31st AIAA Applied Aerodynamics Conference, pp. 1-22, San Diego, Calif, USA, 2013.

[31] J. Patterson, “The cup anemometer," Transactions of the Royal Society of Canada Series III, vol. 20, pp. 1-54, 1926.

[32] R. M. Pinkerton, "Calibration and lag of a Friez type cup anemometer," NACA TN-341, 1930.

[33] J. Hubbard and G. Brescoll, "Aerodynamic investigation of a cup anemometer," NACA TN-502, 1934.

[34] S. P. Fergusson, Harvard Meteorological Studies No. 4. Experimental Studies of Cup Anemometers, Harvard University Press, Cambridge, Mass, USA, 1939.

[35] J. G. Albright and G. E. Klein, "The sensitivity of anemometer cups," Ohio Journal of Science, vol. 41, pp. 70-78, 1941.

[36] L. J. Fritschen, "A sensitive cup-type anemometer," Journal of Applied Meteorology, vol. 6, pp. 695-698, 1967.

[37] D. Lindley, "The design and performance of a 6-cup anemometer," Journal of Applied Meteorology, vol. 14, no. 6, pp. 1135-1145, 1975.

[38] T. J. Lockhart, "Some cup anemometer testing methods," Journal of Atmospheric and Oceanic Technology, vol. 2, no. 4, pp. 680-683, 1985.

[39] T. F. Pedersen and U. S. Paulsen, "Classification of operational characteristics of commercial cup-anemometers," in Proceedings of the European Wind Energy Conference (EWEC '99), pp. 611-615, Nice, France, 1999.

[40] R. S. Hunter, B. M. Petersen, T. F. Pedersen et al., Recommended Practices for Wind Turbine Testing and Evaluation. 11-Wind Speed Measurement and Use of Cup Anemometry, 2003.
[41] F. J. Scrase and P. A. Sheppard, "The errors of cup anemometers in fluctuating winds," Journal of Scientific Instruments, vol. 21, no. 9, article 304, pp. 160-161, 1944.

[42] M. Sanuki, "Experiments of the start and stop of windmill and cup anemometers with particular reference to their over-estimation factors," Papers in Meteorology and Geophysics, vol. 3, pp. 41-53, 1952.

[43] S. Ramachandran, "A theoretical study of cup and vane anemometers-part II," Quarterly Journal of the Royal Meteorological Society, vol. 96, pp. 115-123, 1969.

[44] V. Y. Torochkov and D. Y. Surazhskiy, "Measuring average wind speed," Foreign Technology Division/Wright Patterson AFB FTD-HT-23-341-69, 1969.

[45] D. T. Acheson, "Response of cup and propeller rotors and wind direction vanes to turbulent wind fields," Meteorological Monographs, vol. 11, pp. 252-261, 1970.

[46] N. E. Busch, O. Christensen, L. Kristensen, L. Lading, and S. E. Larsen, "Cups, vanes, propellers, and laser anemometers," in Air-Sea Interaction: Instruments and Methods, F. Dobson, L. Hasse, and R. Davis, Eds., Plenum Press, New York, NY, USA, 1980.

[47] T. Hayashi, "Dynamic response of a cup anemometer," Journal of Atmospheric and Oceanic Technology, vol. 4, no. 2, pp. 281287, 1987.

[48] P. Frenzen, "Fast response cup anemometers for atmospheric turbulence research," in Proceedings of the 8th Symposium on Turbulence and Diffusion, pp. 112-115, American Meteorological Society, 1988.

[49] J. T. Snow, D. E. Lund, M. D. Conner, S. B. Harley, and C. B. Pedigo, "The dynamic response of a wind measuring system," Journal of Atmospheric and Oceanic Technology, vol. 6, no. 1, pp. 140-146, 1989.

[50] R. S. Hunter, "The accuracy of cup anemometer calibration with particular regard to testing wind turbines," Wind Engineering, vol. 14, no. 1, pp. 32-43, 1990.

[51] Skarstein $\varnothing$, A. Collins, and R. Hunter, "Improved dynamic response of cup anemometers using a simple real time recursive algorithm," in Proceedings of the Wind Energy Technology and Implementation (EWEC' '91), F. J. L. Van Hulle, P. T. Smulders, and J. B. Dragt, Eds., pp. 802-806, Elsevier Science, 1992.

[52] L. Kristensen, "The cup anemometer and other exciting instruments, Tech. Rep., Risø-R-615 (EN), Roskilde, Denmark, 1993.

[53] L. Kristensen, "Cups, Props and Vanes," Tech. Rep., Risø-R-766 (EN), Roskilde, Denmark, 1994.

[54] O. Fabian, Fly-Wheel Calibration of Cup-Anemometers. Risø-R797(EN): Contributions From the Department of Meteorology and Wind Energy to the EWEC '94 Conference in Thessaloniki, Greece, 1995.

[55] D. Westermann, "Overspeeding—über das eigentümliche Tiefpaßverhalten von Schalensternanemometern: overspeeding measurements of cup anemometers," DEWI Magazin, pp. 5663, 1996.

[56] T. S. Hristov, S. D. Miller, and C. A. Friehe, "Linear timeinvariant compensation of cup anemometer and vane inertia," Boundary-Layer Meteorology, vol. 97, no. 2, pp. 293-307, 2000.

[57] L. Kristensen, "Measuring higher-order moments with a cup anemometer," Journal of Atmospheric and Oceanic Technology, vol. 17, no. 8, pp. 1139-1148, 2000.

[58] L. Kristensen and O. F. Hansen, "Distance constant of the risø cup anemometer,” Tech. Rep., Risø-R-1320(EN), Roskilde, Denmark, 2002. 
[59] L. Kristensen, O. F. Hansen, and J. Højstrup, "Sampling bias on cup anemometer mean winds," Wind Energy, vol. 6, no. 4, pp. 321-331, 2003.

[60] T. F. Pedersen, "Characterisation and classification of RIS $\varnothing$ P2546 cup anemometer," Tech. Rep., Risø-R-1364 (ed. 2) (EN), Roskilde, Denmark, 2004.

[61] S. Yahaya and J. P. Frangi, "Cup anemometer response to the wind turbulence-measurement of the horizontal wind variance," Annales Geophysicae, vol. 22, no. 10, pp. 3363-3374, 2004.

[62] L. Kristensen and O. F. Hansen, Bias on Horizontal Mean-Wind Speed and Variance Caused by Turbulence Presentation of Main Result, 2005.

[63] A. Bégin-Drolet, J. Ruel, and J. Lemay, "Off-axis characterization of ice-free anemometers," Journal of Wind Engineering and Industrial Aerodynamics, vol. 99, no. 8, pp. 825-832, 2011.

[64] A. Bégin-Drolet, J. Lemay, and J. Ruel, “Time domain modeling of cup anemometers using artificial neural networks," Flow Measurement and Instrumentation, vol. 33, pp. 10-27, 2013.

[65] M. C.-E. Brazier, "Sur la comparabilité des anémomètres," Comptes Rendus de l'Académie des Sciences, vol. 172, pp. 843845, 1921.

[66] C. F. Marvin, "A rational theory of the cup anemometer," Monthly Weather Review, vol. 60, pp. 43-56, 1932.

[67] C. F. Marvin, "Recent advances in anemometry," Monthly Weather Review, vol. 62, pp. 115-120, 1934.

[68] A. F. Spilhaus and C. Rossby, "Analysis of the cup anemometer," Meteorological Course. Professional Notes 7, 1934.

[69] E. L. Deacon, "The over-estimation error of cup anemometers in fluctuating winds," Journal of Scientific Instruments, vol. 28, no. 8, article 303, pp. 231-234, 1951.

[70] P. B. MacCready Jr., "Mean wind speed measurements in turbulence," Journal of Applied Meteorology, vol. 5, pp. 219-225, 1966.

[71] A. B. Bernstein, "A note on the use of cup anemometers in wind profile experiments," Journal of Applied Meteorology, vol. 6, pp. 280-286, 1967.

[72] Y. Izumi and M. L. Barad, "Wind speeds as measured by cup and sonic anemometers and influenced by tower structure," Journal of Applied Meteorology, vol. 9, pp. 851-856, 1970.

[73] D. W. Camp, R. E. Turner, and L. P. Gilchrist, "Response tests of cup, vane, and propeller wind sensors," NASA TM X-64522, 1970.

[74] D. Lindley and A. J. Bowen, "The response of cup and propeller anemometers to fluctuating wind speeds," in Proceedings of the 5th Australasian Conference on Hydraulics and Fluid Mechanics, vol. 1, pp. 269-277, 1974.

[75] H. W. Baynton, "Errors in wind run estimates from rotational anemometers," Bulletin of the American Meteorological Society, vol. 57, no. 9, pp. 1127-1131, 1976.

[76] V. R. Morris, J. C. Barnard, L. L. Wendell, and S. D. Tomich, "Comparison of anemometers for turbulence characterization," Tech. Rep. PNL-SA-21321, CONF-921049-6, 1992.

[77] T. F. Pedersen, J.-Å. Dahlberg, and P. Busche, "ACCUWIND— classification of five cup anemometers according to IEC6140012-1," Tech. Rep., Risø-R-1556(EN), Roskilde, Denmark, 2006.

[78] D. Siegel and J. Lee, "An auto-associative residual processing and K-means clustering approach for anemometer health assessment," International Journal of Prognostics and Health Management, vol. 2, pp. 50-61, 2011.
[79] J. Cassity, C. Aven, and D. Parker, "Applying weibull distribution and discriminant function techniques to predict damaged cup anemometers in the 2011 PHM competition," International Journal of Prognostics and Health Management, vol. 3, pp. 1-7, 2012.

[80] L. Sun, C. Chen, and Q. Cheng, "Feature extraction and pattern identification for anemometer condition diagnosis," International Journal of Prognostics and Health Management, vol. 3, pp. 8-18, 2012.

[81] M. Zlatanovic and V. Zlatanovic, "Long term operation characteristics of NRG \#40 cup anemometers," in Proceedings of the EWEA Annual Event, pp. 1-10, EWEA, 2012.

[82] S. Pindado, A. Barrero-Gil, and A. Sanz, "Cup anemometers'loss of performance due to ageing processes, and its effect on annual energy production (AEP) estimates," Energies, vol. 5, no. 5, pp. 1664-1685, 2012.

[83] J. Wieringa, "A revaluation of the Kansas mast influence on measurements of stress and cup anemometer overspeeding," Boundary-Layer Meteorology, vol. 18, no. 4, pp. 411-430, 1980.

[84] J. C. Wyngaard, J. A. Businger, J. C. Kaimal, and S. E. Larsen, "Comments on 'a revaluation of the Kansas mast influence on measurements of stress and cup anemometer overspeeding'," Boundary-Layer Meteorology, vol. 22, no. 2, pp. 245-250, 1982.

[85] C. J. Moore, "Frequency response corrections for eddy correlation systems," Boundary-Layer Meteorology, vol. 37, no. 1-2, pp. $17-35,1986$.

[86] P. R. Ebert, D. H. Wood, and S. F. Graebe, "Correcting measurements from a cup anemometer and wind vane," in Proceedings of the 12th Australasian Fluid Mechanics Conference, pp. 375-378, Sydney, Australia, 1995.

[87] J. C. Barnard, L. L. Wendell, and V. R. Morris, "Optimal filtering of AC output anemometers," Journal of Atmospheric and Oceanic Technology, vol. 15, no. 6, pp. 1261-1271, 1998.

[88] M. G. Selyaninov, "Dynamic error of rotating flow-rate transducer," Measurement Techniques, vol. 47, no. 6, pp. 571-577, 2004.

[89] F.-U. Dentler, "The effect of rainfall on measurements of mean wind speed with cup anemometers in the surface layer at sea," Boundary-Layer Meteorology, vol. 14, no. 1, pp. 123-130, 1978.

[90] G. Fortin, J. Perron, and A. Ilinca, "Behaviour and modeling of cup anemometers under Icing conditions," in Proceedings of the 11th International Workshop on Atmospheric Icing of Structures, Montréal, Canada, 2005.

[91] E. M. Gates and W. C. Thompson, "Simulated atmospheric rime icing of some wind speed sensors," Journal of Atmospheric and Oceanic Technology, vol. 3, no. 2, pp. 273-282, 1986.

[92] S. Kimura, K. Abe, K. Tsuboi, B. Tammelin, and K. Suzuki, "Aerodynamic characteristics of an iced cup-shaped body," Cold Regions Science and Technology, vol. 33, no. 1, pp. 45-58, 2001.

[93] L. Makkonen, P. Lehtonen, and L. Helle, "Anemometry in icing conditions," Journal of Atmospheric and Oceanic Technology, vol. 18, no. 9, pp. 1457-1469, 2001.

[94] S. Pindado, A. Sanz, and A. Wery, "Deviation of cup and propeller anemometer calibration results with air density," Energies, vol. 5, no. 3, pp. 683-701, 2012.

[95] M. Hobby, M. Gascoyne, J. H. Marsham et al., "The fennec automatic weather station (AWS) network: monitoring the saharan climate system," Journal of Atmospheric and Oceanic Technology, vol. 30, no. 4, pp. 709-724, 2013.

[96] J. C. Wyngaard, "The effects of probe-induced flow distortion of atmospheric turbulence measurements," Journal of Applied Meteorology, vol. 20, no. 7, pp. 784-794, 1981. 
[97] M. O. L. Hansen and B. M. Pedersen, "Influence of the meteorology mast on a cup anemometer," Journal of Solar Energy Engineering, vol. 121, no. 2, pp. 128-131, 1999.

[98] W. D. Lubitz, "Effects of tower shadowing on anemometer data," in Proceedings of the 11th Americas Conference on Wind Engineering, San Juan, Puerto Rico, June 2009.

[99] W. V. Burt, "A comparison of the responses of identical cup anemometersmounted on a spar and a toroid buoy," Journal of Physical Oceanography, vol. 5, no. 4, pp. 789-792, 1975.

[100] B. M. Pedersen, K. S. Hansen, S. Øye, M. Brinch, and O. Fabian, "Some experimental investigations on the influence of the mounting arrangements on the accuracy of cup-anemometer measurements," Journal of Wind Engineering and Industrial Aerodynamics, vol. 39, no. 1-3, pp. 373-383, 1992.

[101] S. Orlando, A. Bale, and D. A. Johnson, "Experimental study of the effect of tower shadow on anemometer readings," Journal of Wind Engineering and Industrial Aerodynamics, vol. 99, no. 1, pp. 1-6, 2011.

[102] R. N. Farrugia and T. Sant, "Modelling wind speeds for cup anemometers mounted on opposite sides of a lattice tower: a case study," Journal of Wind Engineering and Industrial Aerodynamics, vol. 115, pp. 173-183, 2013.

[103] L. Kristensen, M. Casanova, M. S. Courtney, and I. Troen, "In search of a gust definition," Boundary-Layer Meteorology, vol. 55, no. 1-2, pp. 91-107, 1991.

[104] D. W. Camp, "Preliminary results of anemometer comparison tests,” Tech. Rep., NASA TM X-53451, 1966.

[105] E. L. Petersen, N. G. Mortensen, L. Landberg, J. Hùjstrup, and H. P. Frank, "Wind power meteorology. Part II: siting and models," Wind Energy, vol. 1, pp. 55-72, 1998.

[106] K. H. Papadopoulos, N. C. Stefantos, U. S. Paulsen, and E. Morfiadakis, "Effects of turbulence and flow inclination on the performance of cup anemometers in the field," Boundary-Layer Meteorology, vol. 101, no. 1, pp. 77-107, 2001.

[107] R. S. Hunter, T. F. Pedersen, P. Dunbabin et al., "European wind turbine testing procedure developments task 1: measurement method to verify wind turbine performance characteristics," Tech. Rep., Risø-R-1209(EN), Roskilde, Denmark, 2001.

[108] U. S. Paulsen, N. G. Mortensen, J. C. Hansen, U. S. Said, and A. A. E.-S. Moussa, "Field calibration of cup anemometers," in Proceedings of the European Wind Energy Conference and Exhibition (EWEC '07), pp. 7-10, Milan, Italy, 2007.

[109] R. Wagner, M. Courtney, J. Gottschall, and P. Lindelöw-Marsden, "Accounting for the speed shear in wind turbine power performance measurement," Wind Energy, vol. 14, no. 8, pp. 9931004, 2011.

[110] S. Lang and E. McKeogh, "LIDAR and SODAR measurements of wind speed and direction in upland terrain for wind energy purposes," Remote Sensing, vol. 3, no. 9, pp. 1871-1901, 2011.

[111] S. Bradley, "Aspects of the correlation between sodar and mast instrument winds," Journal of Atmospheric and Oceanic Technology, vol. 30, pp. 2241-2247, 2013.

[112] C. Hasager, D. Stein, M. Courtney et al., "Hub height ocean winds over the North Sea observed by the NORSEWInD lidar array: measuring techniques, quality control and data management," Remote Sensing, vol. 5, pp. 4280-4303, 2013.

[113] J. Sanz Rodrigo, F. Borbón Guillén, P. Gómez Arranz, M. S. Courtney, R. Wagner, and E. Dupont, "Multi-site testing and evaluation of remote sensing instruments for wind energy applications," Renewable Energy, vol. 53, pp. 200-210, 2013.
[114] T. R. Robinson, "On the determination of the constants of the cup anemometer by experiments with a whirling machine," Philosophical Transactions of the Royal Society, vol. 169, pp. 777822, 1878.

[115] T. R. Robinson, "On the determination of the constants of the cup anemometer by experiments with a whirling machine. Part II," Philosophical Transactions of the Royal Society, vol. 171, pp. 1055-1070, 1880.

[116] M. C. Brazier -E, "Sur la variation des indications des anémomètres Robinson et Richard en fonction de l'inclinaison du vent," Comptes rendus de l'Académie des sciences, vol. 170, pp. 610-612, 1920.

[117] F. López Peña and R. J. Duro, "A virtual instrument for automatic anemometer calibration with ANN based supervision," IEEE Transactions on Instrumentation and Measurement, vol. 52, no. 3, pp. 654-661, 2003.

[118] P. J. Eecen and M. De Noord, "Uncertainties in cup anemometer calibrations type A and type B uncertainties," Tech. Rep., ECNC-05-066, 2005.

[119] A. Piccato, R. Malvano, and P. G. Spazzini, "Metrological features of the rotating low-speed anemometer calibration facility at INRIM," Metrologia, vol. 47, no. 1, pp. 47-57, 2010.

[120] A. Piccato, P. G. Spazzini, and R. Malvano, "Cup anemometer calibration: effect of flow velocity distribution," Metrologia, vol. 48, no. 5, article 015, pp. 343-351, 2011.

[121] R. V. Coquilla, "Calibration program for wind sensors in wind energy applications," in Proceedings of the NCSL International Conference, 2012.

[122] T. J. Lockhart, "Anemometer performance determined by ASTM methods," Journal of Atmospheric and Oceanic Technology, vol. 4, no. 1, pp. 160-169, 1987.

[123] L. Makkonen and L. Helle, "Calibration of anemometers-an uncertainty in wind energy resource assessment," in Proceedings of the 5th European Wind Energy Association Conference (EWEA '94), pp. 273-278, 1994.

[124] ASTM International, Standard Test Method for Determining the Performance of a Cup Anemometer or Propeller Anemometer (ASTM D 5096-02), ASTM International, West Conshohocken, $\mathrm{Pa}$, USA, 2002.

[125] J.-A. Dahlberg, "An investigation of wind tunnel blockage effects on cup anemometer calibrations," Tech. Rep., FOI-R2006-SE, 2006.

[126] R. V. Coquilla and J. Obermeier, "Calibration speed range for rotating anemometers used in wind energy applications," in Proceedings of the 46th AIAA Aerospace Sciences Meeting and Exhibit, pp. 2-7, American Institute of Aeronautics and Astronautics, January 2008.

[127] D. Westermann, N. Balaresque, and P. Busche, Systematic Deviation in Anemometer Calibration Due to Geometrical Interference, Deutsche WindGuard, Varel, Germany, 2011.

[128] O. F. Hansen, S. O. Hansen, and L. Kristensen, "Wind tunnel calibration of cup anemometers," in Proceedings of the AWEA Wind Power Conference, pp. 1-22, Atlanta, Ga, USA, 2012.

[129] A. Gkanias and A. Katsanevakis, "Investigation of the wind tunnel blockage effect on cup anemometer calibration," in Proceedings of the EWEA Conference, EWEA, 2012.

[130] G. A. McBean, "Instrument requirements for eddy correlation measurements," Journal of Applied Meteorology, vol. 11, no. 7, pp. 1078-1084, 1972 . 
[131] P. A. Sheppard, D. T. Tribble, and J. R. Garratt, "Studies of turbulence in the surface layer over water (Lough Neagh). Part I. Instrumentation, programme, profiles," Quarterly Journal of the Royal Meteorological Society, vol. 98, pp. 627-641, 1972.

[132] P. Frenzen, "Fast-response cup anemometer features cosine response," Tech. Rep., AEC-NASA Tech Brief 68-10202, 1968.

[133] J. B. Wellman, "A folding rotating cup anemometer," Jet Propulsion Laboratory, vol. 37-53, pp. 133-143, 1968.

[134] D. Mazzarella, "An inventory of specifications for wind measuring instruments," Bulletin of the American Meteorological Society, vol. 53, pp. 860-871, 1972.

[135] T. W. Choon, C. Prakash, L. E. Aik, and T. T. Hin, "Development of low wind speed anemometer," International Journal on Advanced Science, Engineering and Information Technology, vol. 2, pp. 39-42, 2012.

[136] S. Pindado and J. Cubas, "Some developments on cup anemometer aerodynamics," Defect and Diffusion Forum, vol. 348, pp. 179-185, 2014.

[137] ENAC, “Anexo Técnico, Acreditación No 134/LC10. 095," Instituto Universitario de Microgravedad, Ignacio da Riva, 2012, https://www.enac.es/documents/7020/67cfa73f-f539-4c138172-986daad8514a. 

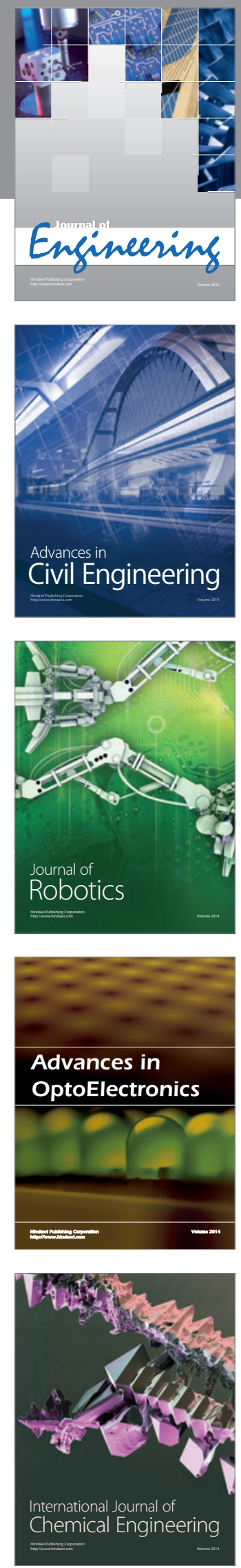

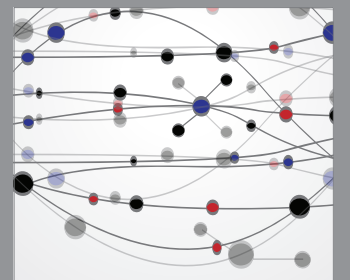

The Scientific World Journal
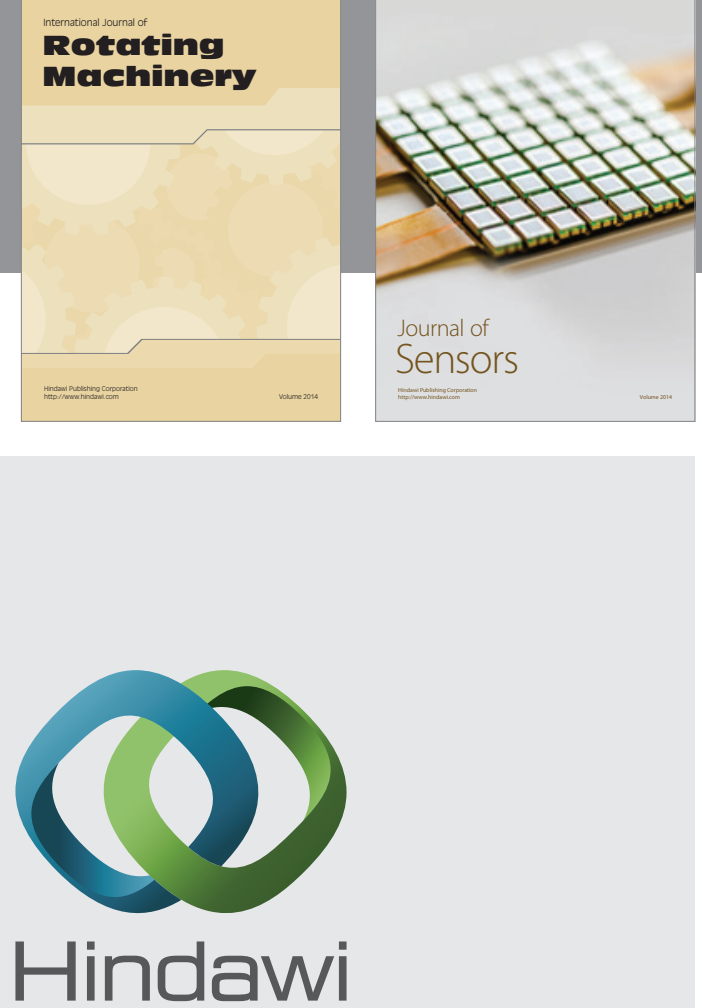

Submit your manuscripts at http://www.hindawi.com
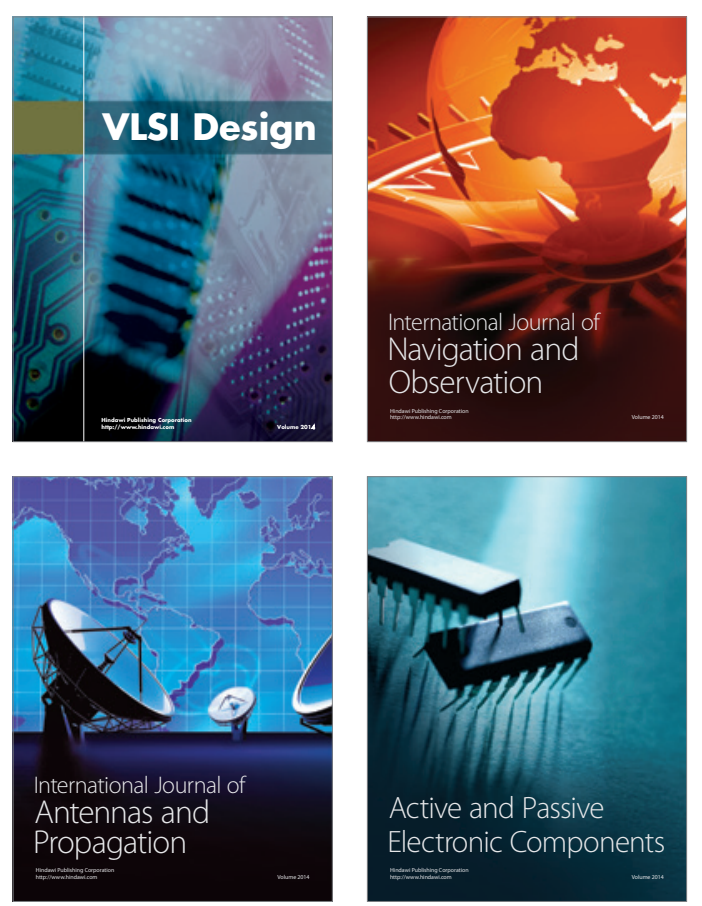
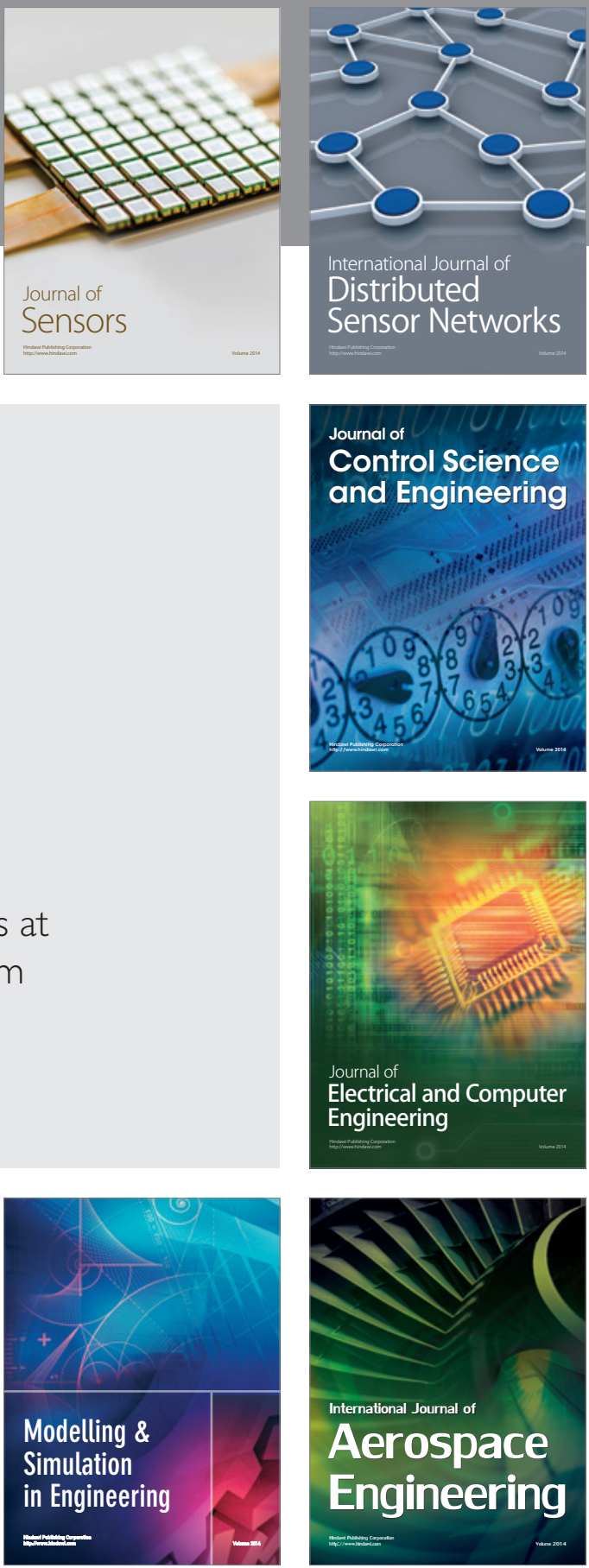

Journal of

Control Science

and Engineering
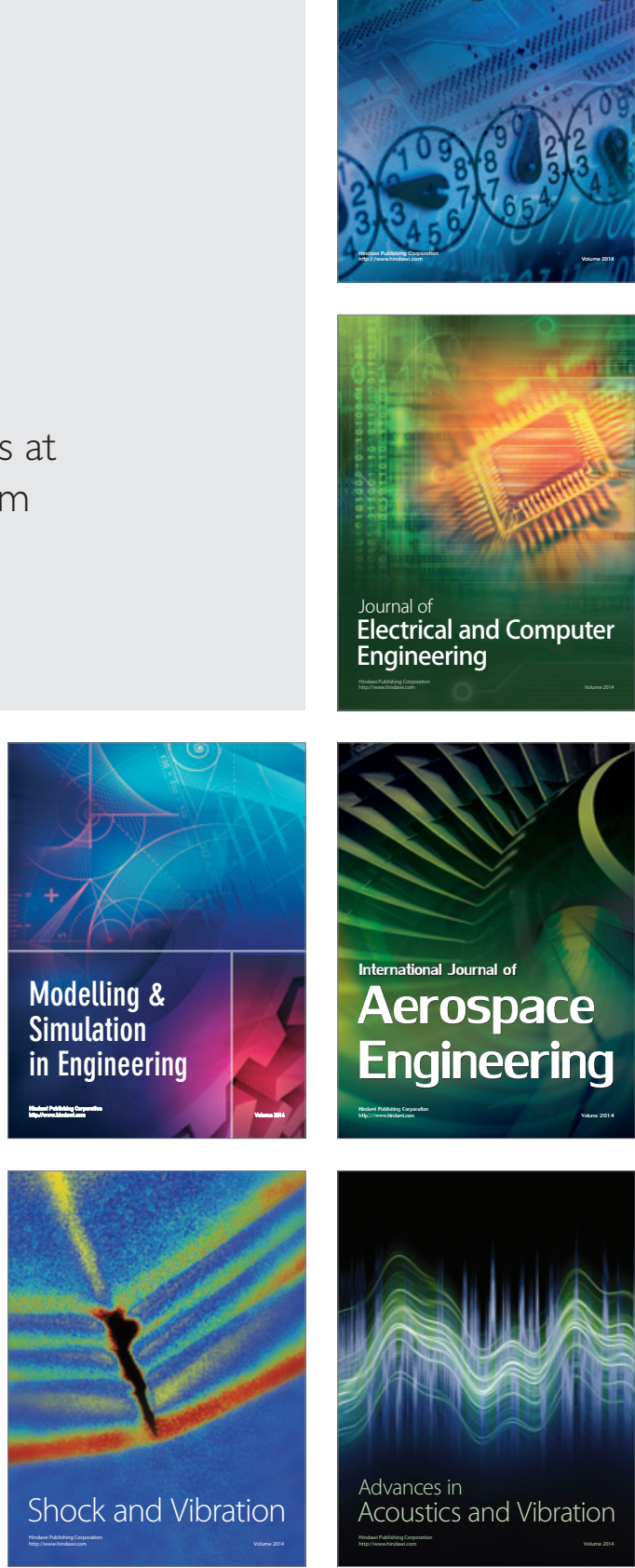